Supporting Information

\title{
Degradable Polyphosphoramidate via Ring-Opening Metathesis Polymerization
}

Yifei Liang, ${ }^{1}$ Hao Sun, ${ }^{\star 1,2}$ Wei Cao, ${ }^{1,2}$ Matthew P. Thompson, ${ }^{1,2}$ Nathan C. Gianneschi ${ }^{\star 1,2}$

'Department of Chemistry, International Institute for Nanotechnology, Simpson-Querrey Institute, Chemistry of Life Processes Institute, Lurie Cancer Center, Northwestern University, 2145 Sheridan Road, Evanston, Illinois 60208, United States

${ }^{2}$ Department of Biomedical Engineering, Materials Science \& Engineering, and Pharmacology, Northwestern University, 2145 Sheridan Road, Evanston, Illinois 60208, United States

${ }^{*}$ Corresponding author:

Dr. Hao Sun, email: haolu.sun@northwestern.edu

Prof. Nathan C. Gianneschi, email: nathan.gianneschi@northwestern.edu 


\section{Table of Contents}

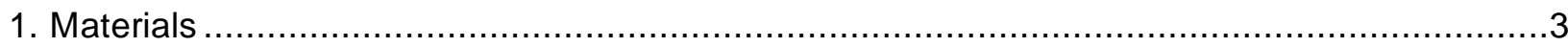

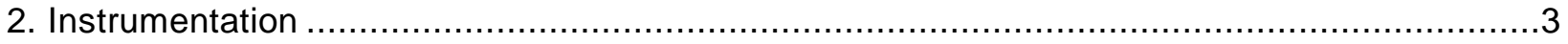

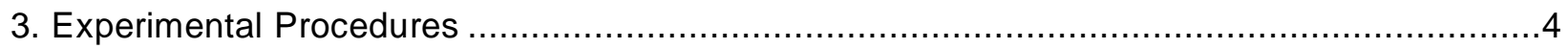

3.1. Synthesis of Diazaphosphepine Based Cyclic Olefin Monomer .................................

3.2. Representative Procedure for PTDO Homopolymerization ....................................6

3.3. Representative Procedure for Random Copolymerization of PTDO with Norbornene .......6

3.4. Representative Procedure for Block Copolymerization of PTDO with Norbornene ...........7

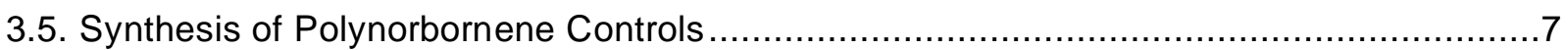

3.6. Degradation of PTDO and PPTDO via Acid Hydrolysis .......................................

3.7. Degradation of NB-PTDO Copolymer and Polynorbornene via Acid Hydrolysis...............8

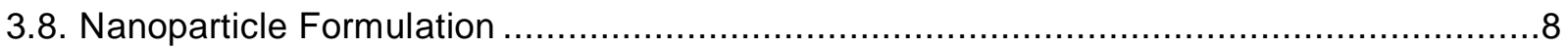

4. Ring Strain via Density Functional Theory Calculation .........................................

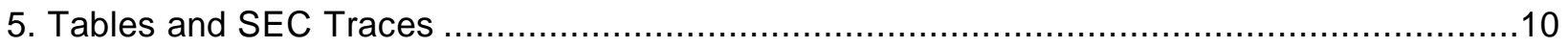

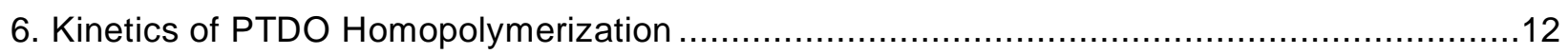

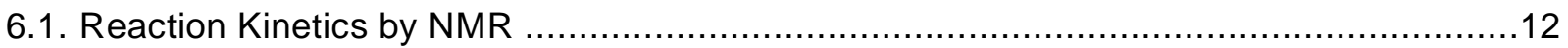

6.2. Example of Monomer Conversion Calculation ..............................................

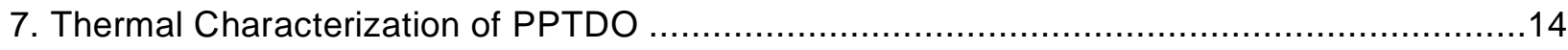

8. Kinetics of PTDO and PPTDO Degradation via Acid Hydrolysis .................................15

8.1. Kinetics of PTDO Degradation via Acid Hydrolysis .............................................16

8.2. Kinetics of PPTDO Degradation via Acid Hydrolysis ............................................18

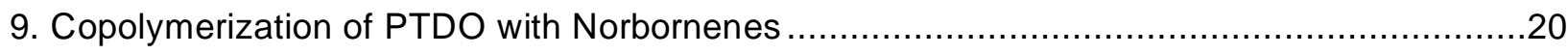

9.1. Random Copolymerization of PTDO with Norbornenes ........................................20

9.2. Block Copolymerization of PTDO with Norbornenes ..........................................22

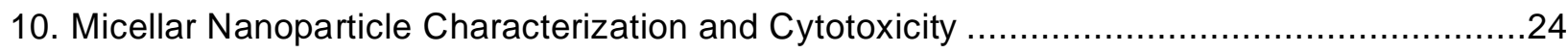

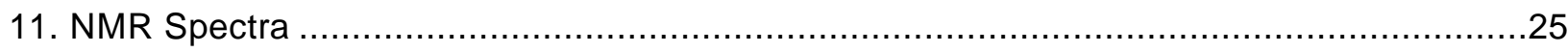

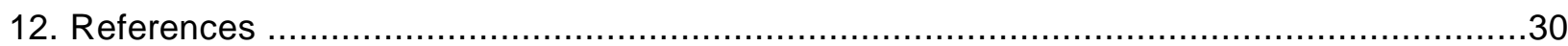




\section{Materials}

Organic solvents, including methanol (MeOH), ethanol, dimethyl sulfoxide (DMSO) and diethyl ether were purchased from either Fisher Scientific or Sigma-Aldrich and used without purification. Anhydrous solvents, including dichloromethane (DCM) and dimethyformamide (DMF) were obtained from a Grubb's type solvent drying system prior to use. The reagents were acquired from commercial vendors, including Sigma-Aldrich, Thermo Fisher Scientific, Acros Organics, and Cambridge Isotope Laboratories Inc. All the chemicals were used as received. Phenyl and oligo(ethylene glycol) bearing norbornenes, as well as Grubbs initiator $\left(\mathrm{IMes} \mathrm{H}_{2}\right)\left(\mathrm{C}_{5} \mathrm{H}_{5} \mathrm{~N}\right)_{2}(\mathrm{Cl})_{2} \mathrm{Ru}=\mathrm{CHPh}$ (I) were prepared as previously described. ${ }^{1}$ Flash column chromatography was performed using silica gel $60(40-63 \mu \mathrm{m}, 230-400$ mesh, $60 \AA)$ purchased from Fisher Scientific. Analytical thin-layer chromatography (TLC) was carried out on silica gel 60G F254 glass plates purchased from EMD Millipore and visualized by observation of fluorescence under ultraviolet light and staining with $\mathrm{KMnO}_{4}$ as a developing agent. Dulbecco's phosphate buffered saline (without $\mathrm{Ca}^{2+}, \mathrm{Mg}^{2+}$ ) was purchased from Corning. Transmission electron microscopy (TEM) was performed on 400 mesh carbon grids purchased from Ted Pella, Inc. For cell studies, CellTiter-Blue ${ }^{\circledR}$ was purchased from Promega Corporation and HeLa cells were purchased from American Type Culture Collection (ATCC).

\section{Instrumentation}

Nuclear Magnetic Resonance (NMR): ${ }^{1} \mathrm{H}-\mathrm{NMR}$ and ${ }^{31} \mathrm{P}-\mathrm{NMR}$ spectra were recorded either on a $500 \mathrm{MHz}$ Bruker Advance III HD system equipped with a TXO Prodigy probe or on a $400 \mathrm{MHz}$ Bruker Advance III HD Nanobay system with SampleXpress autosampler. The residual solvent peaks were used as the reference signals $\left(\mathrm{D}_{2} \mathrm{O}: \delta 4.79\right.$ for ${ }^{1} \mathrm{H}-\mathrm{NMR}$; DMSO- $d_{6}$ : $\delta 2.50$ for ${ }^{1} \mathrm{H}$ NMR).

Electrospray Ionization Mass Spectrometry (ESI-MS): ESI-MS spectra were acquired on a Bruker AmaZon SL configured with an ESI source in both negative and positive ionization mode.

Transmission Electron Microscope (TEM): Five microliters of sample were applied to a 400 mesh carbon grid (Ted Pella, Inc.) that had been glow discharged for 15 seconds. Five microliters of 2 wt.\% uranyl acetate solution was then applied and wicked away for staining. Dry state TEM of nanoparticles were conducted on a Hitachi HT-7700 biological TEM at an acceleration voltage of $120 \mathrm{kV}$. The images were recorded with a slow-scan charge-coupled device (CCD) camera (Veleta $2 \mathrm{k} \times 2 \mathrm{k}$ ). 
Thermal Analysis: Thermogravimetric analysis (TGA) was performed using Netzsch's Simultaneous Thermal Analysis (STA) system 449 F1 "Jupiter" simultaneous thermal analyzer under helium ( $50 \mathrm{~mL} / \mathrm{min}$ ) with a heating rate of $10^{\circ} \mathrm{C} / \mathrm{min}$. DSC measurements were performed using Mettler Toledo Polymer DSC under nitrogen. Two thermal cycles (-50 to $\left.200{ }^{\circ} \mathrm{C}\right)$ with heating and cooling rates of $10{ }^{\circ} \mathrm{C} / \mathrm{min}$ were performed. Glass transition temperature was obtained from the second heating scan after the thermal history was removed.

Size-Exclusion Chromatography (SEC): SEC measurements were carried out in HPLC grade dimethylformamide (DMF) with $0.05 \mathrm{M} \mathrm{LiBr}$ at $60{ }^{\circ} \mathrm{C}$ on a Phenomenex Phenogel $5,1 \mathrm{~K}-75 \mathrm{~K}, 300$ x $7.80 \mathrm{~mm}$ column in series with a Phenomex Phenogel 5, 10K-1000K, $300 \times 7.80 \mathrm{~mm}$ column. The detection system consisted of a L-2420 Hitachi UV-Vis Detector operating at $280 \mathrm{~nm}$, a Wyatt Optilab T-rEX refractive index detector operating at $658 \mathrm{~nm}$ and a Wyatt DAWN® HELEOS $\AA$ II light scattering detector operating at $659 \mathrm{~nm}$. Absolute molecular weight and dispersity were calculated using the Wyatt ASTRA software with $\mathrm{dn} / \mathrm{dc}$ values determined by assuming $100 \%$ mass recovery during SEC analysis. The $\mathrm{dn} / \mathrm{dc}$ of polyphosphoramidate (PPTDO) in DMF with $0.05 \mathrm{M} \mathrm{LiBr}$ was measured to be $0.1174 \mathrm{~mL} / \mathrm{g}$.

Fluorescence Measurement: CellTiter-Blue ${ }^{\circledR}$ fluorescence measurements were recorded using a Perkin Elmer EnSpire multimode Plate Reader.

\section{Experimental Procedures}

\subsection{Synthesis of Diazaphosphepine Based Cyclic Olefin Monomer}

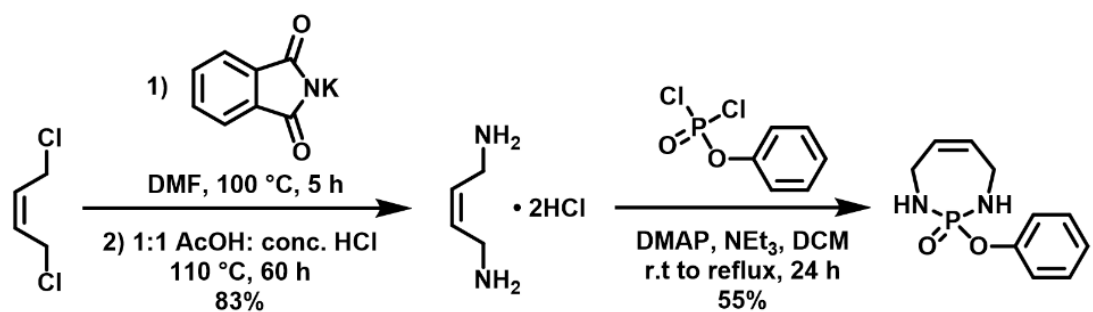

cis-1,4-diamino-2-butene-2HCl:

The compound was prepared following a procedure slightly modified from the literature. ${ }^{2}$ To a suspension of potassium phthalimide $\left(23.7 \mathrm{~g}, 128 \mathrm{mmol}, 2.0\right.$ equiv.) in $90 \mathrm{~mL}$ of DMF at $0{ }^{\circ} \mathrm{C}$, cis1,4-dichloro-2-butene ( $8.0 \mathrm{~g}, 64 \mathrm{mmol}, 1.0$ equiv.) was added dropwise over $30 \mathrm{~min}$. The mixture was stirred at room temperature (r.t) for $10 \mathrm{~min}$ and then heated to $100^{\circ} \mathrm{C}$ for $5 \mathrm{~h}$. The reaction 
mixture was cooled to r.t, poured into $400 \mathrm{~mL}$ of ice/water and filtered to collect the solid. The residue was transferred to a $250 \mathrm{~mL}$ round bottom flask where $120 \mathrm{~mL}$ of acetic acid: concentrated $\mathrm{HCl}(1: 1 \mathrm{v} / \mathrm{v})$ solution was added and then heated to reflux for $60 \mathrm{~h}$. After the precipitate was removed by filtration, the filtrate was concentrated under vacuum and recrystallized from warm ethanol to yield the product as a slightly brown solid (8.49 g, 83\%). ${ }^{1} \mathrm{H}-\mathrm{NMR}\left(500 \mathrm{MHz}, \mathrm{D}_{2} \mathrm{O}\right): \delta$ (ppm) 5.90 (ddt, J = 5.4, 4.4, $1.0 \mathrm{~Hz}, 2 \mathrm{H}), 3.78-3.76(\mathrm{~m}, 4 \mathrm{H})$.

\section{2-phenoxy-1,3,4,7-tetrahydro-1,3,2-diazaphosphepine 2-oxide (PTDO):}

The compound was prepared following a procedure slightly modified from the literature. ${ }^{3} \mathrm{~A} 2 \mathrm{~L}$ round bottom flask was flame dried, cooled and charged with $800 \mathrm{~mL}$ of dry DCM. To the flask, phenyl dichlorophosphate (2.20 g, $10.4 \mathrm{mmol}, 1.0$ equiv.) was added with stirring and cooled to $0{ }^{\circ} \mathrm{C}$. DMAP (127 mg, $1.04 \mathrm{mmol}, 0.1$ equiv.) and triethylamine (10.9 mL, $78.1 \mathrm{mmol}, 7.5$ equiv.) were slowly added. After $5 \mathrm{~min}$, the ice bath was removed, and the solution was stirred at room temperature (r.t) for another 15 min until a slightly yellow color was observed. Cis-1,4-diamino-2butene. $2 \mathrm{HCl}(2.00 \mathrm{~g}, 12.5 \mathrm{mmol}$. 1.2 equiv.) was separately dissolved in $50 \mathrm{~mL}$ of dry DCM and triethylamine $(5.08 \mathrm{~mL}, 36.4 \mathrm{mmol}, 3.5$ equiv.). The mixture was slowly added to the phenyl dichlorophosphate solution over $30 \mathrm{~min}$. The resulting mixture was stirred at r.t for $30 \mathrm{~min}$ and heated to reflux under $\mathrm{N}_{2}$ for $24 \mathrm{~h}$. The reaction was then cooled and concentrated under vacuum to about $200 \mathrm{~mL}$. Water was added and the aqueous layer was extracted three times with DCM. The combined organic layer was dried over $\mathrm{MgSO}_{4}$ and concentrated to dryness. The residue was purified via column chromatography $(10 \% \mathrm{MeOH}$ in $\mathrm{DCM})$ to yield the product as a slightly yellow solid (1.24 g, 53\%). ${ }^{1} \mathrm{H}-\mathrm{NMR}\left(500 \mathrm{MHz}\right.$, DMSO- $\left.d_{6}\right)$ : $\delta$ (ppm) $7.37-7.30$ (m, 2H), 7.17 (dq, $\mathrm{J}=7.7,1.2 \mathrm{~Hz}, 2 \mathrm{H}), 7.12(\mathrm{ddd}, \mathrm{J}=8.4,6.8,1.0 \mathrm{~Hz}, 1 \mathrm{H}), 5.57(\mathrm{t}, \mathrm{J}=2.3 \mathrm{~Hz}, 2 \mathrm{H}), 5.38-5.28(\mathrm{~m}$, $2 \mathrm{H}$ ), 3.45 (ddt, J = 19.7, 7.0, $2.2 \mathrm{~Hz}, 4 \mathrm{H}) .{ }^{13} \mathrm{C}-\mathrm{NMR}(126 \mathrm{MHz}$, DMSO-d6): $\delta$ (ppm) 151.90, 151.85, 129.82, 129.42, 124.26, 121.19, 121.15, 38.68. ${ }^{31} \mathrm{P}-\mathrm{NMR}$ (202 MHz, DMSO-d $)$ : $\delta$ (ppm) 17.67. ESI-MS: calculated for $\mathrm{C}_{10} \mathrm{H}_{13} \mathrm{~N}_{2} \mathrm{O}_{2} \mathrm{P}[\mathrm{M}+\mathrm{Na}]^{+}$247.06; found 246.99. 


\subsection{Representative Procedure for PTDO Homopolymerization}
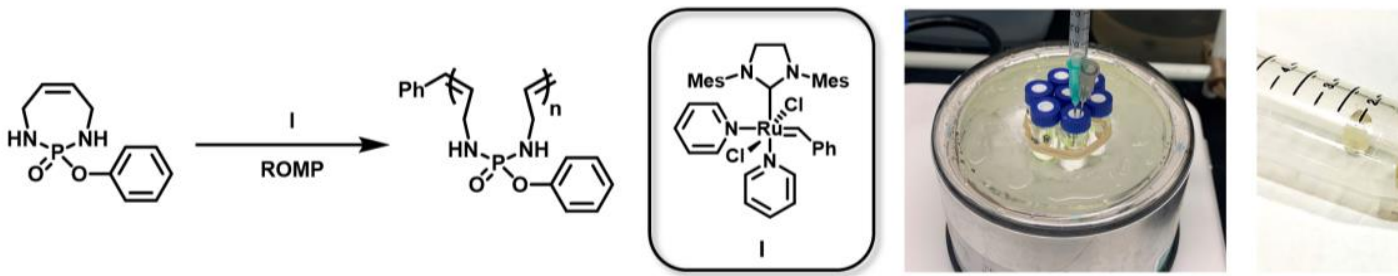

PTDO has limited solubility in pure DCM, thus $\mathrm{MeOH}$ was doped in to achieve desired monomer concentrations. A mixed solvent of MeOH/DCM (10/90, v/v) was dried over $3 \AA$ molecular sieves overnight and freeze-pump-thawed three times to degas immediately prior to polymerization. Grubbs initiator $\left(\mathrm{IMesH}_{2}\right)\left(\mathrm{C}_{5} \mathrm{H}_{5} \mathrm{~N}\right)_{2}(\mathrm{Cl})_{2} \mathrm{Ru}=\mathrm{CHPh}$ (I) $(1.64 \mathrm{mg}, 1.0$ equiv.) and PTDO (50.4 mg, 100 equiv.) were weighed separately in two HPLC type vials containing stir bars. Both vials and the solvent were transferred to a glovebox operated under $\mathrm{N}_{2}$. Initiator I was dissolved in $150 \mu \mathrm{L}$ of solvent, giving a green solution. PTDO was dissolved in $300 \mu \mathrm{L}$ of solvent under stirring, resulting in a clear solution. Both solutions (with the caps on to prevent contact with air) were removed from the glovebox. The initiator solution was cooled in an ice/water bath $\left(2^{\circ} \mathrm{C}\right)$ for $5 \mathrm{~min}$ before the addition of the PTDO solution. A color change from green to slightly brown was observed 5 min post addition. After $5 \mathrm{~h}, 100 \mu \mathrm{L}$ of ethyl vinyl ether (EVE) was added and the solution was stirred for $30 \mathrm{~min}$ to terminate the polymerization. An aliquot of the reaction was taken out, reduced under vacuum and dissolved in DMSO- $d_{6}$ for NMR analysis. The rest of the reaction mixture was precipitated in ice-cold diethyl ether and centrifuged to collect the solid. The resulting solid was re-dissolved in a mixed solvent of $\mathrm{MeOH} / \mathrm{DCM}(10 / 90, \mathrm{v} / \mathrm{v})$ and precipitated in diethyl ether again. The same procedure was repeated two times to remove unreacted monomers. The product was dried under vacuum to yield the PPTDO as a yellow solid.

\subsection{Representative Procedure for Random Copolymerization of PTDO with Norbornene}

A mixed solvent of $\mathrm{MeOH} / \mathrm{DCM}(5 / 95, \mathrm{v} / \mathrm{v})$ was dried over $3 \AA$ molecular sieves overnight and freeze-pump-thawed three times immediately prior to polymerization. The phenyl bearing norbornene NBPh (18.8 mg, 50 equiv.), and PTDO (16.6 mg, 50 equiv.) monomers were added into a HPLC vial. Initiator I (1.08 mg, 1.0 equiv.) was weighed in a separate HPLC vial. The reagents and solvent were transferred to the glovebox operated under $\mathrm{N}_{2}$. Each of the reagents were completely dissolved with the solvent (I: $200 \mu \mathrm{L}$; NBPh and PTDO mixture: $300 \mu \mathrm{L}$ ), capped and removed from the glovebox. The initiator solution was cooled in an ice/water bath $\left(2^{\circ} \mathrm{C}\right)$ for 
$5 \mathrm{~min}$ and then the monomer mixture was added. After $5 \mathrm{~h}$, the reaction was terminated with 100 $\mu \mathrm{L}$ of EVE. After $30 \mathrm{~min}$, an aliquot of the reaction was taken out, concentrated under vacuum and dissolved in DMSO- $d_{6}$ for NMR analysis. The rest of the reaction mixture was precipitated in ice-cold diethyl ether and centrifuged to collect the solid. The resulting solid was re-dissolved in a mixed solvent of $\mathrm{MeOH} / \mathrm{DCM}(5 / 95, \mathrm{v} / \mathrm{v})$ and precipitated in diethyl ether again. The same procedure was repeated two times to remove the unreacted monomers. The solid was dried under vacuum to yield the $\mathrm{NBPh}_{42}-\mathrm{CO}-\mathrm{PTDO}_{32}$ random copolymer.

\subsection{Representative Procedure for Block Copolymerization of PTDO with Norbornene}

A mixed solvent of MeOH/DCM (10/90, v/v) was dried over $3 \AA$ molecular sieves overnight and freeze-pump-thawed three times immediately prior to polymerization. Initiator I (1.96 mg, 1.0 equiv.), phenyl bearing norbornene NBPh (34.1 mg, 50 equiv.), and PTDO (30.2 mg, 50 equiv.) were weighed in separate HPLC vials. The reagents and solvent were transferred to the glovebox operated under $\mathrm{N}_{2}$. Each of the reagents were completely dissolved with the solvent (I: $100 \mu \mathrm{L}$; NBPh: $150 \mu \mathrm{L}$; PTDO: $200 \mu \mathrm{L}$ ). NBPh was added to I, resulting in an immediate color change from green to brown. After $1 \mathrm{~h}$, both the reaction mixture and PTDO solution were removed from the glovebox. The reaction mixture was cooled in an ice/water bath $\left(2{ }^{\circ} \mathrm{C}\right)$ for $5 \mathrm{~min}$, followed by addition of the PTDO solution. After $3 \mathrm{~h}$, the reaction was quenched with $100 \mu \mathrm{L}$ of EVE. After 30 min, an aliquot of the reaction was removed, concentrated under vacuum and dissolved in DMSO$d_{6}$ for NMR analysis. The NBPh$h_{50}-b-\mathrm{PTDO}_{25}$ block copolymer was precipitated and dried following the same procedures as the random copolymer (vide supra).

\subsection{Synthesis of Polynorbornene Controls}

Homopolymerizations of the norbornene monomers were setup in parallel with each of the copolymerizations outlined above. The same feed ratio of I to norbornene was used in each case. A solution of the norbornene monomer was added to a solution of $\mathbf{I}$ in the glovebox with the reaction being terminated with EVE after $1 \mathrm{~h}$. An aliquot of the polymerization was removed, concentrated under vacuum and dissolved in DMSO- $d_{6}$ for NMR analysis. The polymer was precipitated and dried following the same procedures as the random copolymer (vide supra). 


\subsection{Degradation of PTDO and PPTDO via Acid Hydrolysis}

PTDO and PPTDO were dissolved separately in $0.6 \mathrm{~mL}$ DMSO- $d_{6}$ at a concentration of $4 \mathrm{mg} / \mathrm{mL}$. $40 \mu \mathrm{L}$ of $4 \mathrm{M} \mathrm{HCl}$ was added to each solution to yield a final concentration of $0.25 \mathrm{M} \mathrm{HCl}$ in DMSO$d_{6}$. The solution was transferred to an NMR tube for ${ }^{1} \mathrm{H}$ - and ${ }^{31} \mathrm{P}-\mathrm{NMR}$ analysis.

\subsection{Degradation of NB-PTDO Copolymer and Polynorbornene via Acid Hydrolysis}

Each of the NB-PTDO copolymers and polynorbornenes were dissolved in $0.45 \mathrm{~mL}$ DMSO- $d_{6}$ at a concentration of $4 \mathrm{mg} / \mathrm{mL}$. $20 \mu \mathrm{L}$ of $12 \mathrm{M} \mathrm{HCl}$ was added to each solution to yield a final concentration of $0.5 \mathrm{M} \mathrm{HCl}$ in DMSO- $d_{6}$. The resulting solution was stirred at room temperature for $24 \mathrm{~h}$. Excess $\mathrm{MgSO}_{4}$ was added and the mixture was vortexed. The mixture was allowed to sit for $10 \mathrm{~min}$ then centrifuged. The clear top layer was collected, filtered and concentrated under vacuum. The residue was dissolved in DMF with $0.05 \mathrm{M} \mathrm{LiBr}$ for SEC-MALS analysis.

\subsection{Nanoparticle Formulation}

$2.5 \mathrm{mg}$ of polymer was dissolved in $0.6 \mathrm{~mL}$ DMSO. 1X Dulbecco's phosphate-buffered saline (DPBS) was added via a syringe pump at the speed $50 \mu \mathrm{L} / \mathrm{h}$ until reaching $30 \%$ DPBS in DMSO $(\mathrm{v} / \mathrm{v})$. The solution was left stirring overnight then transferred into SnakeSkin ${ }^{\mathrm{TM}}$ Dialysis Tubing (3.5K MWCO) and dialyzed against DPBS for $48 \mathrm{~h}$ with three buffer changes. The resulting solution had a $1.3 \mathrm{mg} / \mathrm{mL}$ polymer concentration based on initial polymer loading and final solution volume.

\subsection{Cell Viability Assay}

HeLa cells were grown in Dulbecco's Modified Eagle's Medium (DMEM) supplemented with 10\% fetal bovine serum (FBS), and $1 \%$ penicillin-streptomycin. Cells were maintained at $37{ }^{\circ} \mathrm{C}$ and $5 \%$ $\mathrm{CO}_{2}$ with a relative humidity of $95 \%$. HeLa cells were plated in 96 -well plates at a density of 7500 cells per well and then left to attach for $24 \mathrm{~h}$. Subsequently, the cells were treated with the nanoparticles at various concentrations for $24 \mathrm{~h}$ followed by washing 3 times with phosphatebuffered saline (PBS). CellTiter-Blue ${ }^{\circledR}$ at $10 \%(\mathrm{v} / \mathrm{v})$ in complete media was added to each well and incubated for $2 \mathrm{~h}$ to allow the metabolic cells to convert resazurin to fluorescent resorufin. The fluorescent signal (Excitation wavelength: $560 \mathrm{~nm}$; Emission wavelength: $600 \mathrm{~nm}$ ) was then analyzed by a plate reader. Four replicates were performed for each independent sample. 10\% 
DMSO was used as a positive control and untreated cells in complete medium was used as a negative control. Viability is reported as a percentage of untreated cells.

\section{Ring Strain via Density Functional Theory Calculation}

Density functional theory (DFT) calculations were performed using Spartan $14 .{ }^{4,5}$ Geometry optimizations of reactants and product were performed at the B3LYP/6-31 $\mathrm{g}(\mathrm{d})$ level of theory. The conventional B3LYP functional has been proven to generate adequate geometries but perform poorly in energy calculations. Therefore, the energies were refined with the $\omega$ B97X-D functional including dispersion corrections and a 6-31 $\mathrm{g}(\mathrm{d})$ basis set. The enthalpy or heat of formation has been estimated as the energy difference between the total energy of the ringopened molecule and the energy of the isolated reactants (PTDO + ethylene). DCM was used as the solvent for geometry optimizations and energy calculations.

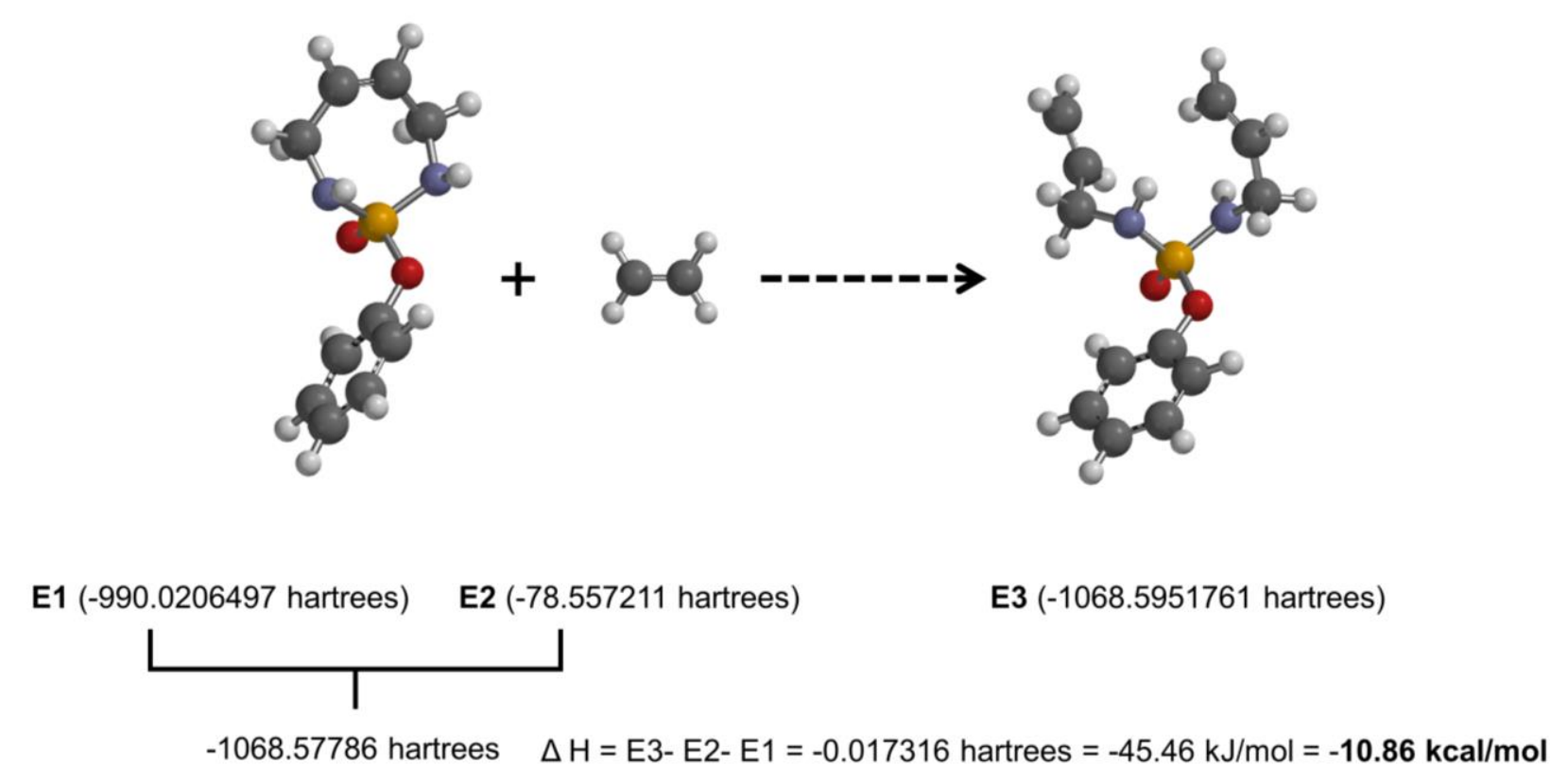

Figure S1. Optimized geometries of the reactants and products calculated by density functional theory and the corresponding energies used to calculate the ring strain of PTDO. 


\section{Tables and SEC Traces}

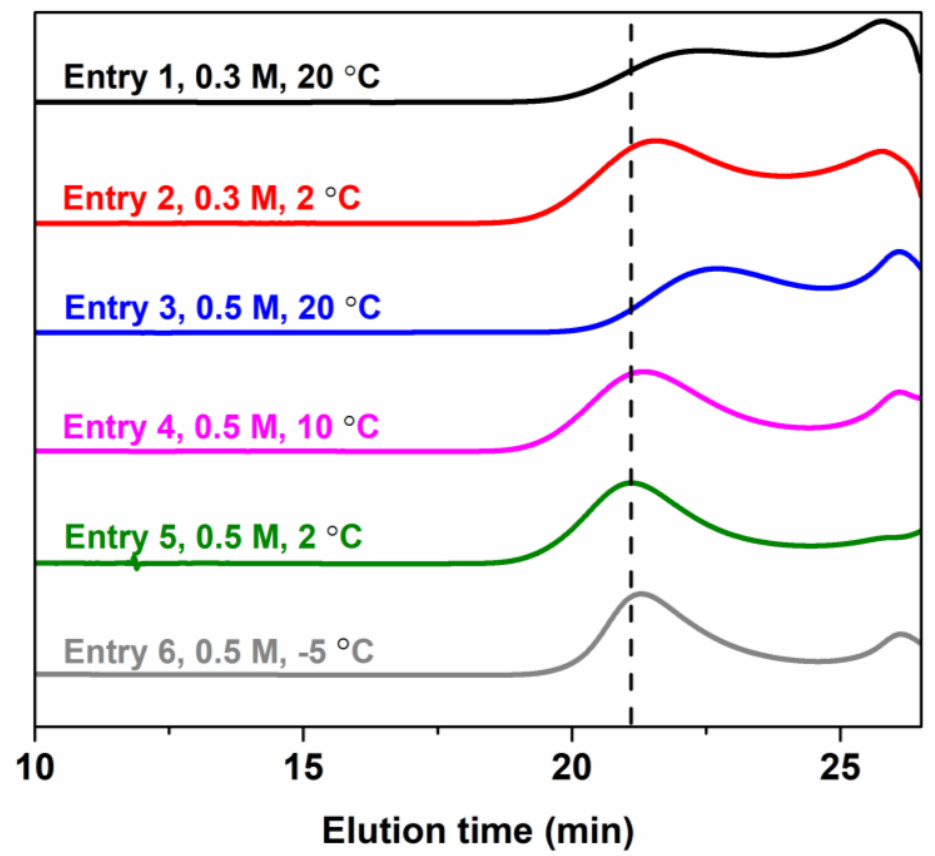

Figure S2. SEC traces of PTDO polymerized under different reaction conditions with I in accordance with Table 1.
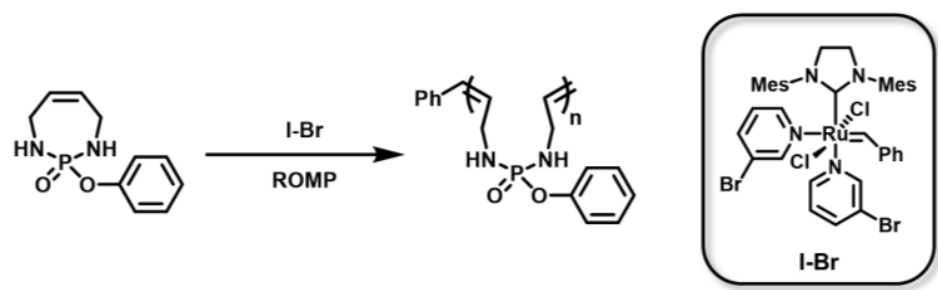

Table S1. ROMP of PTDO under varying temperatures initiated with I-Br.

\begin{tabular}{lllllllll}
\hline Entry & $\mathrm{T}\left({ }^{\circ} \mathrm{C}\right)$ & {$[\mathrm{M}]_{0}(\mathrm{M})$} & {$[\mathrm{M}]:[\mathrm{cat}]$} & Time $(\mathrm{h})$ & Conv. & $\begin{array}{l}M_{n, \text { theo }} \\
(\mathrm{kDa})\end{array}$ & $\begin{array}{l}M_{n, \text { MALS }} \\
(\mathrm{kDa})\end{array}$ & $\Xi$ \\
\hline 1 & 40 & 0.3 & $100: 1$ & 5 & $30 \%$ & 6.7 & 3.1 & 1.44 \\
2 & 20 & 0.3 & $100: 1$ & 5 & $41 \%$ & 9.2 & 3.5 & 1.62 \\
3 & 2 & 0.3 & $100: 1$ & 5 & $62 \%$ & 14.0 & 12.5 & 1.36 \\
\hline
\end{tabular}




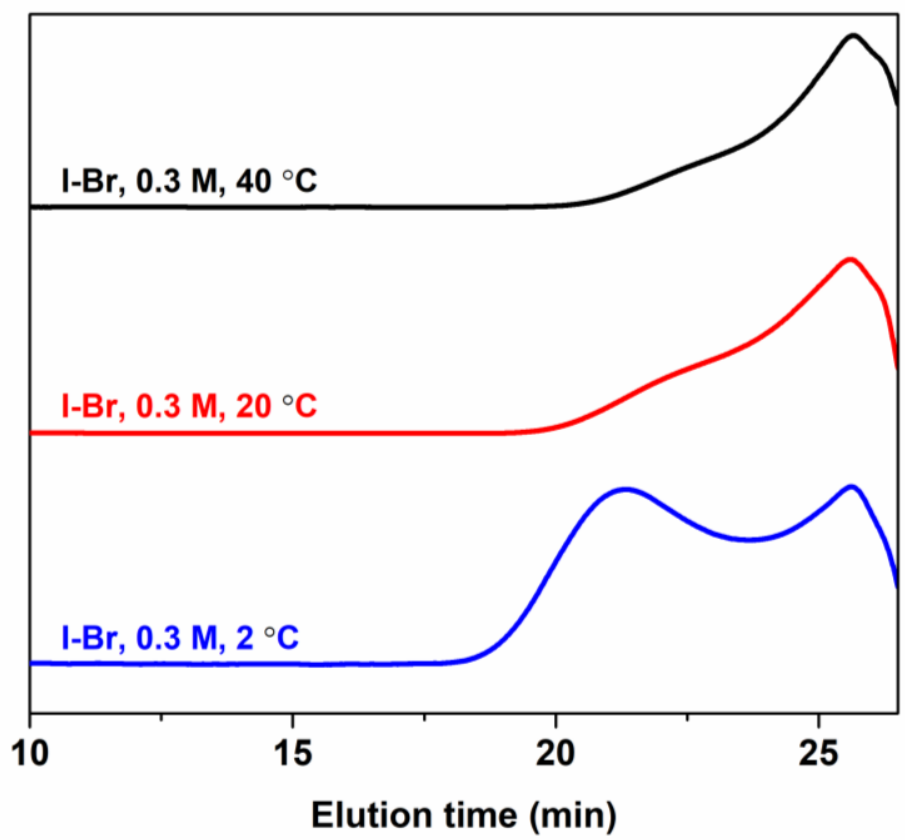

Figure S3. SEC traces of PTDO polymerized under different reaction conditions with I-Br.

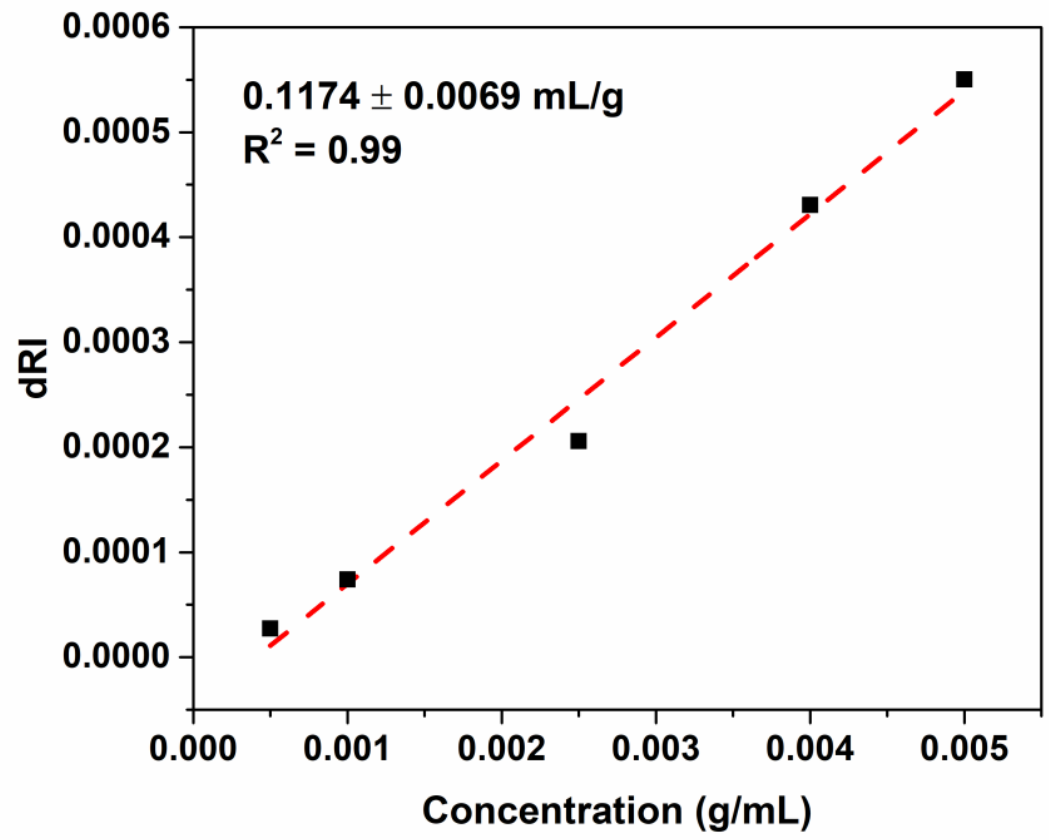

Figure S4. $\mathrm{dn} / \mathrm{dc}$ measurement of PPTDO (DP = 94) in DMF with $0.05 \mathrm{M} \mathrm{LiBr}$. Five different polymer concentrations: $5.0,4.0,2.5,1.0,0.5 \mathrm{mg} / \mathrm{mL}$ were used. 


\section{Kinetics of PTDO Homopolymerization}

\subsection{Reaction Kinetics by NMR}

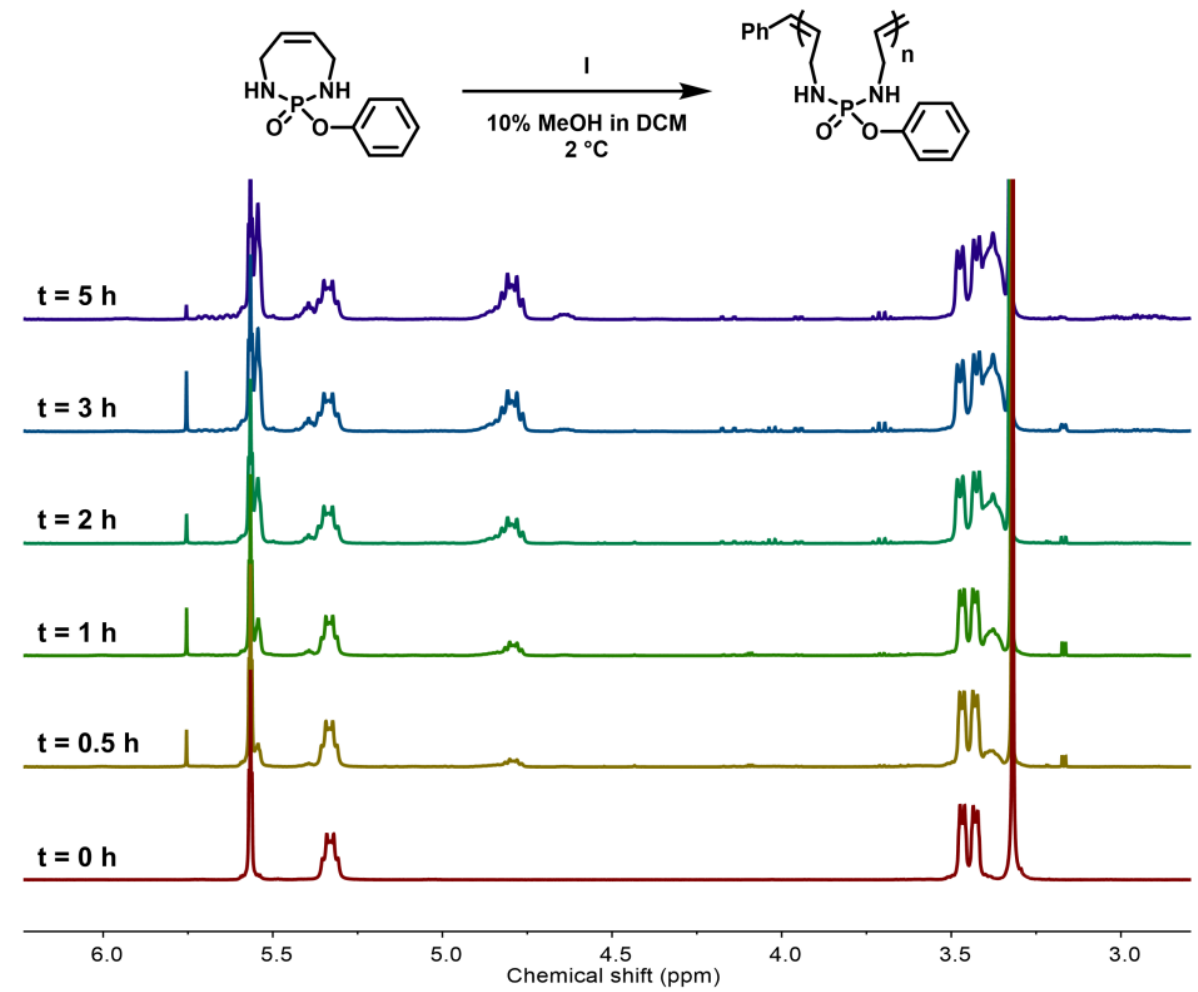

Figure S5. ${ }^{1} \mathrm{H}-\mathrm{NMR}$ analysis of PTDO homopolymerization quenched at different times.

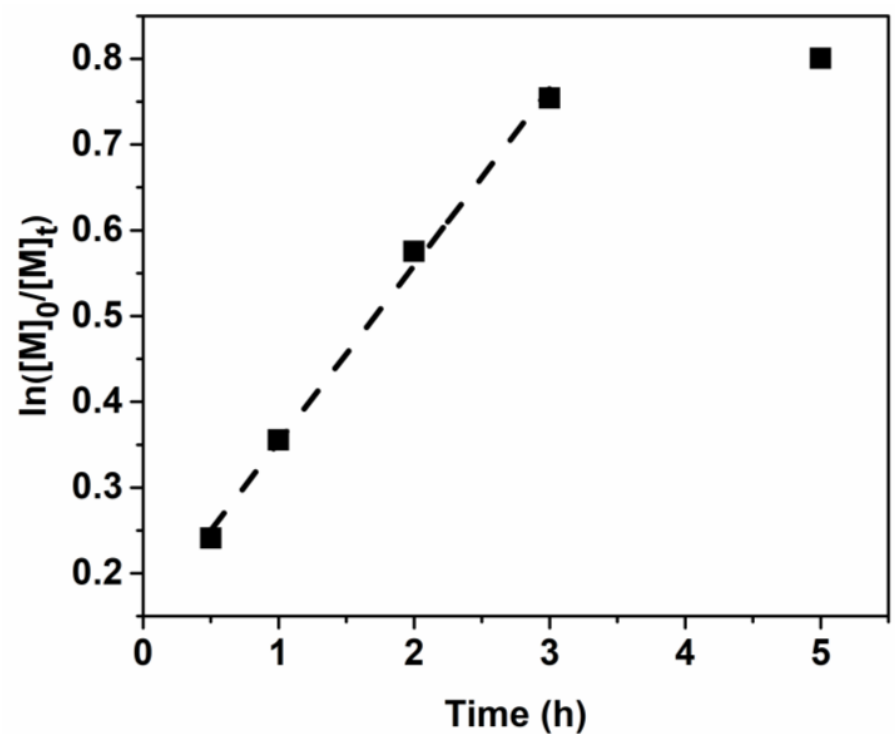

Figure S6. Plot of $\ln \left([\mathrm{M}]_{0} /[\mathrm{M}]_{\mathrm{t}}\right)$ versus time with $\mathrm{R}^{2}=0.997$. 


\subsection{Example of Monomer Conversion Calculation}

Calculation of monomer conversion for the polymerizations of PTDO was made based on the assumption that the chemical shift of the aromatic protons at $\delta=7.33 \mathrm{ppm}$ did not change before and after polymerization, giving a total integration of 2 which can serve as an internal standard. Thus, the integrations of other signals are as following:

$\mathrm{I}_{\text {vinyl }}=\mathrm{I}_{\mathrm{a}}($ unreacted monomer $)+\mathrm{I}_{\mathrm{a}^{\prime}}($ polymer $) \approx 2$

$I_{\text {methylene }}=\mathrm{I}_{\mathrm{b}}($ unreacted monomer $)+\mathrm{I}_{\mathrm{b}^{\prime}}($ polymer $) \approx 4$

$I_{\mathrm{NH}}=\mathrm{I}_{\mathrm{c}}($ unreacted monomer $)+\mathrm{I}_{\mathrm{c}^{\prime}}($ polymer $) \approx 2$

The monomer conversion M\% was calculated based on the following equation:

$$
\mathrm{M} \%=\left[\left(I_{a} / I_{a}+I_{a^{\prime}}\right)+\left(I_{b} / I_{b}+I_{b^{\prime}}\right)+\left(I_{c} / I_{c}+I_{c^{\prime}}\right)\right] / 3
$$

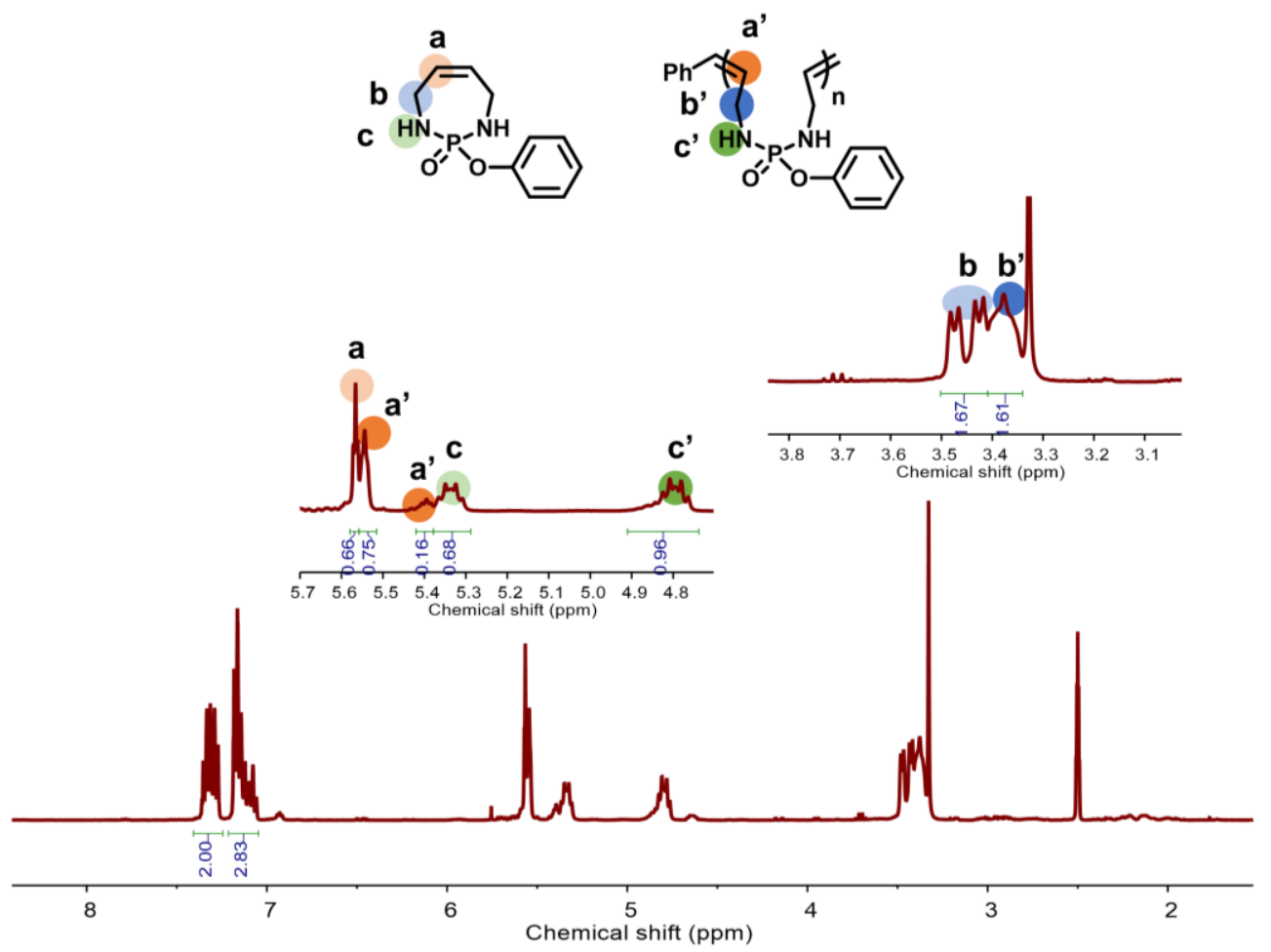

Figure S7. ${ }^{1} \mathrm{H}-\mathrm{NMR}$ determination of monomer conversion for the polymerization of PTDO. In this example, the conversion was calculated to be $M \%=55 \%$ based on the equation above. The integration of a' signal at $5.54 \mathrm{ppm}$ (trans-olefin) and $5.40 \mathrm{ppm}$ (cis-olefin) afforded an E/Z ratio of $5: 1$. 


\section{Thermal Characterization of PPTDO}

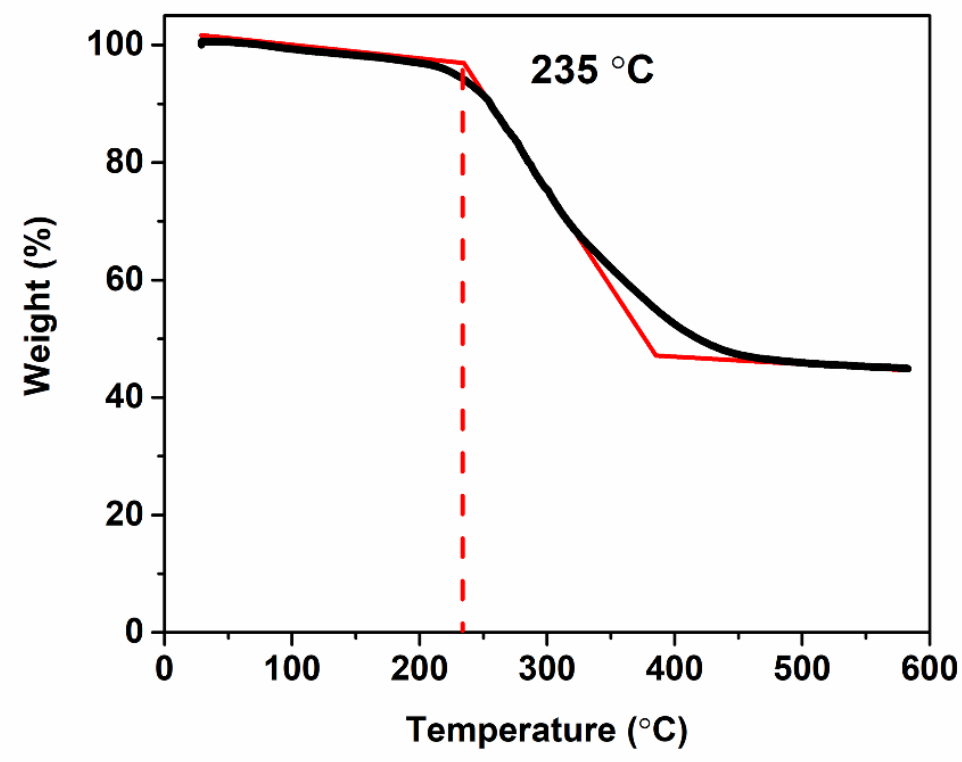

Figure S8. Thermogravimetric analysis of PPTDO (DP = 94) under helium atmosphere with a heating rate of $10^{\circ} \mathrm{C} / \mathrm{min}$. Polymer begins to decompose at $235^{\circ} \mathrm{C}$.

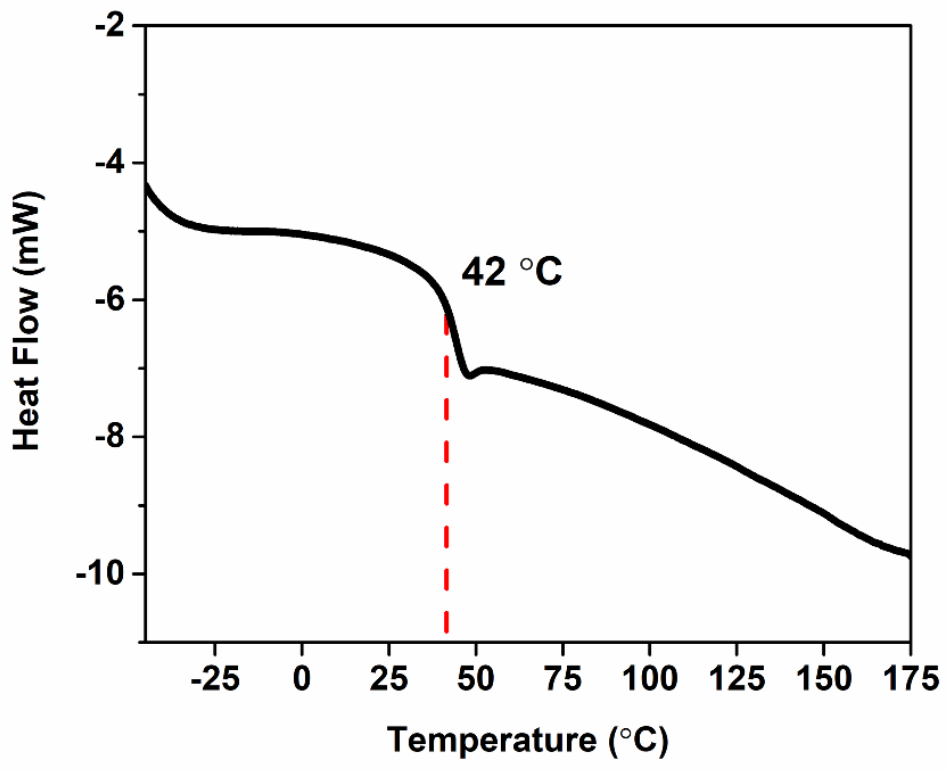

Figure S9. Differential scanning calorimetry thermogram of PPTDO (DP = 94). The second heating scan under nitrogen at a heating rate of $10{ }^{\circ} \mathrm{C} / \mathrm{min}$ estimates a glass transition temperature of $42^{\circ} \mathrm{C}$. 
8. Kinetics of PTDO and PPTDO Degradation via Acid Hydrolysis
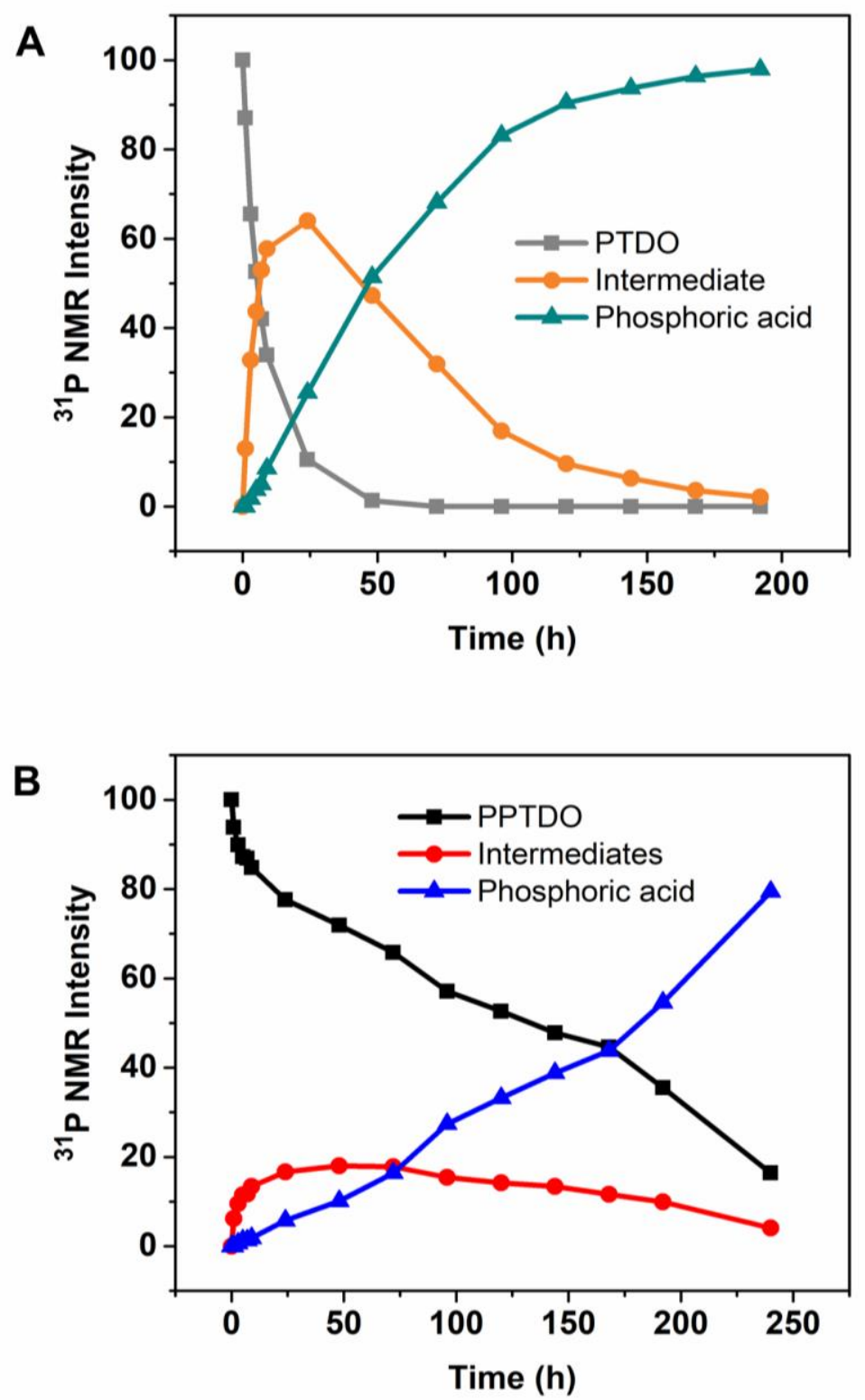

Figure S10. PTDO and PPTDO degradation monitored by ${ }^{31} \mathrm{P}-\mathrm{NMR}$ spectroscopy. 


\subsection{Kinetics of PTDO Degradation via Acid Hydrolysis}

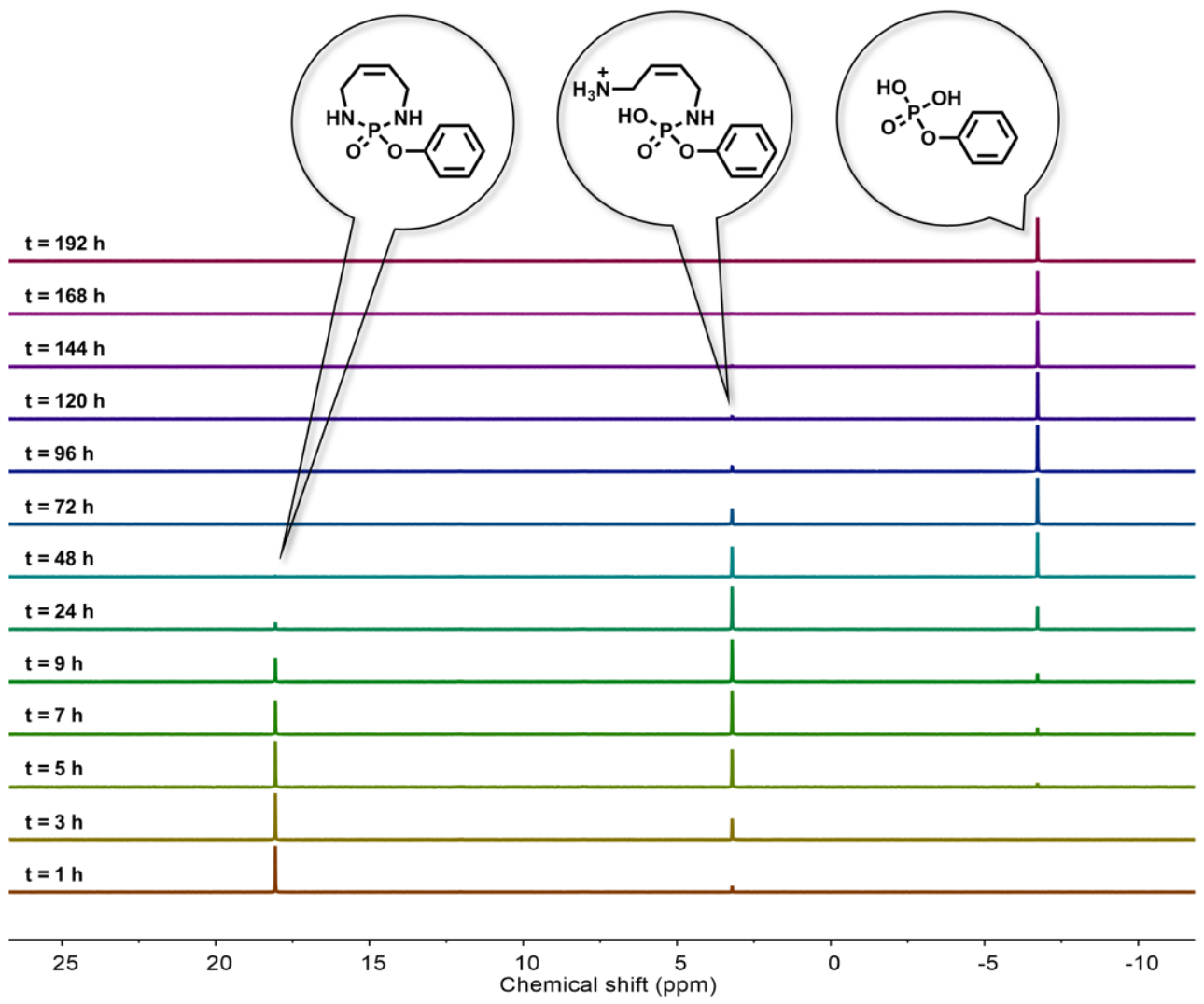

Figure S11. ${ }^{31} \mathrm{P}-\mathrm{NMR}$ spectra of PTDO degradation at different times in $0.25 \mathrm{M} \mathrm{HCl}$ in DMSO-d6. The decrease in signal at $18.07 \mathrm{ppm}$ and the increase in signal at $-6.72 \mathrm{ppm}$ is indicative of the conversion of PTDO into phenylphosphoric acid via acid hydrolysis. 


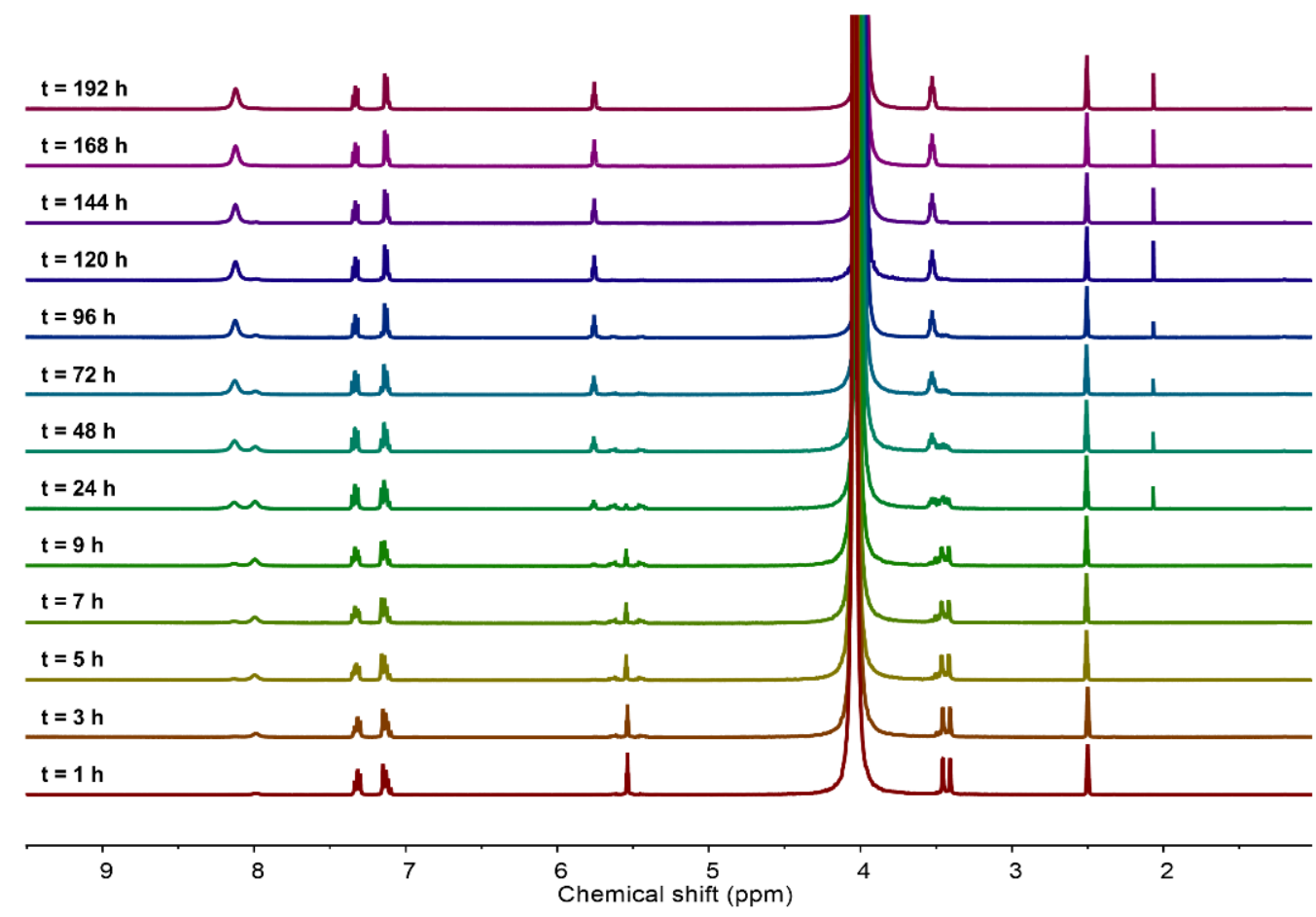

Figure S12. ${ }^{1} \mathrm{H}-\mathrm{NMR}$ spectra of PTDO degradation at different times in $0.25 \mathrm{M} \mathrm{HCl}$ in DMSO- $d_{6}$. The decrease of the cyclic alkene proton signal at $5.54 \mathrm{ppm}$ is indicative of hydrolysis of PTDO.

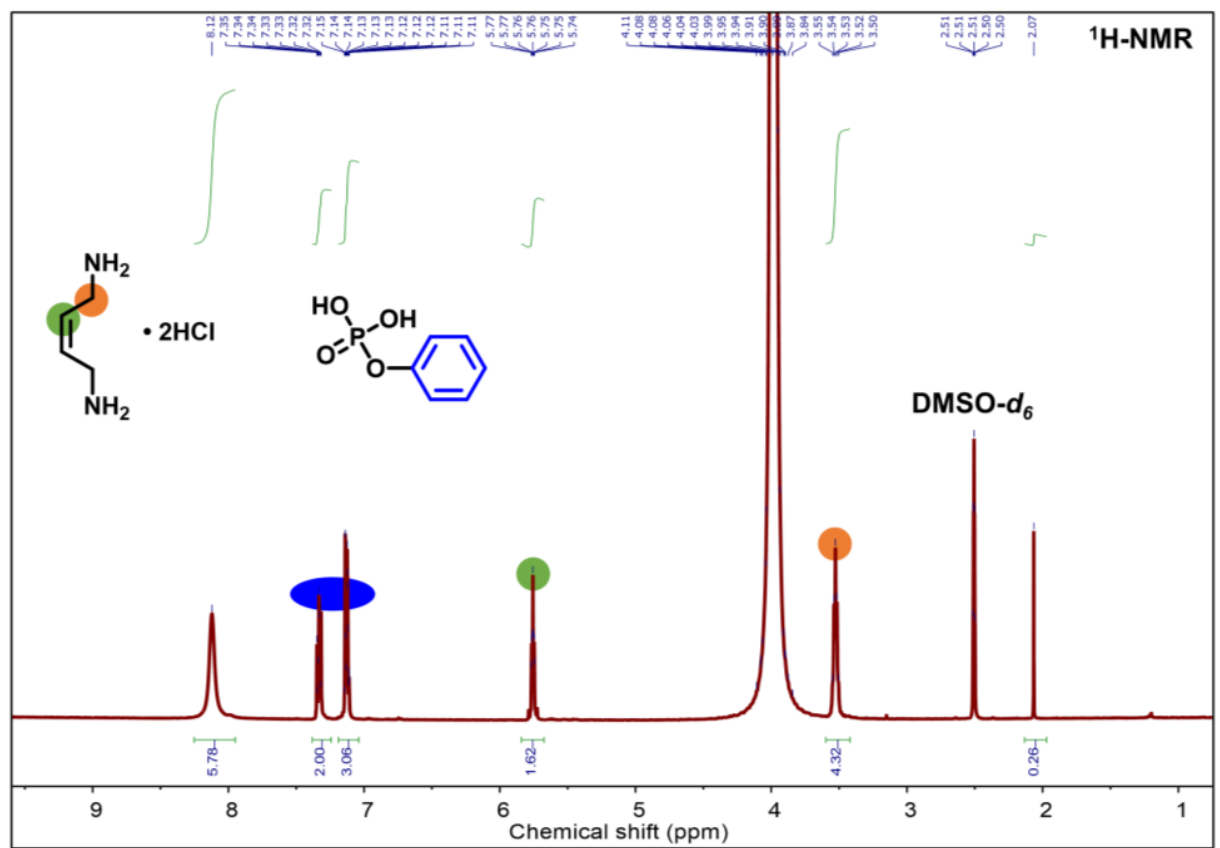

Figure S13. ${ }^{1} \mathrm{H}-\mathrm{NMR}$ spectrum of PTDO degradation post $192 \mathrm{~h}$ of acid treatment. 


\subsection{Kinetics of PPTDO Degradation via Acid Hydrolysis}

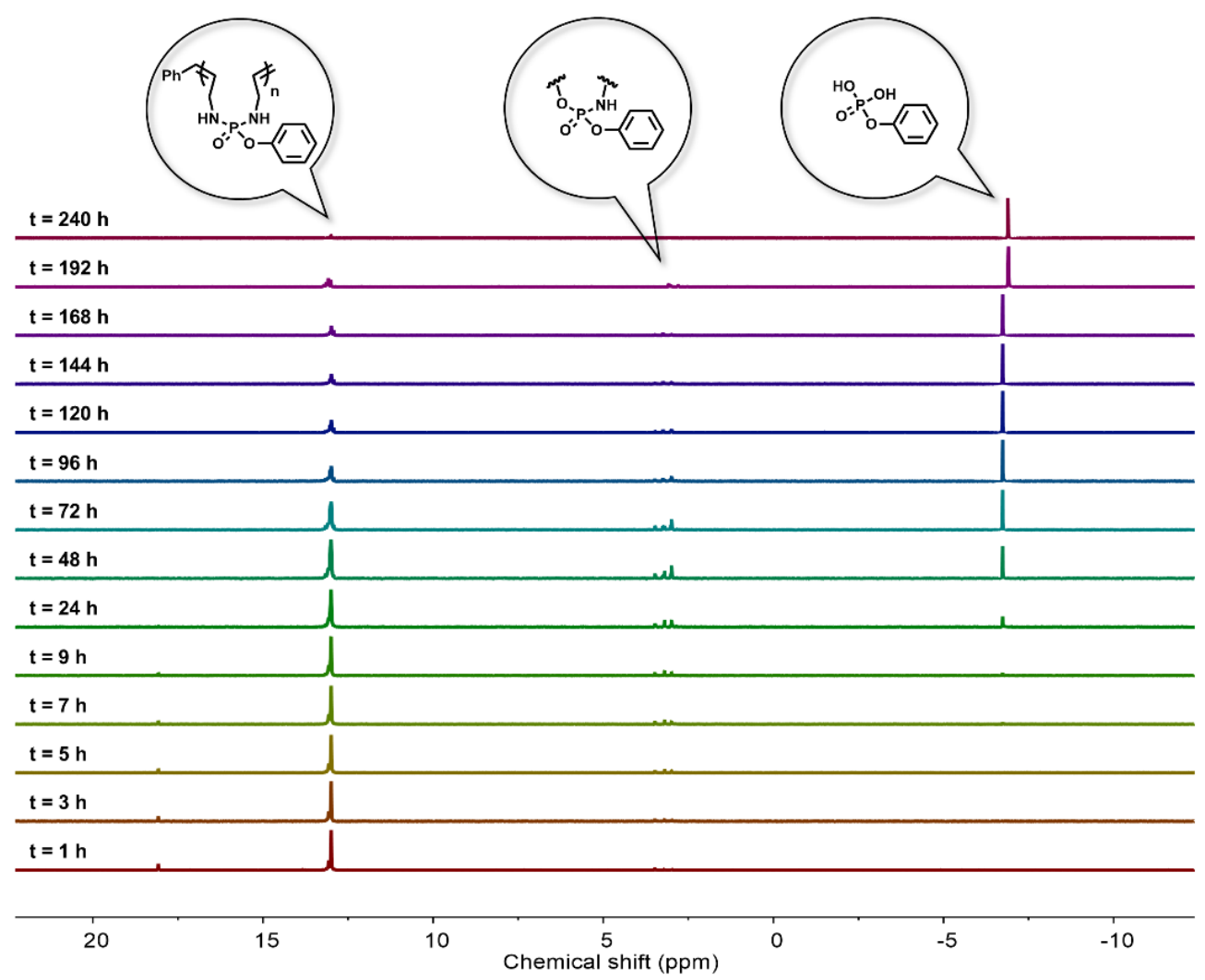

Figure S14. ${ }^{31} \mathrm{P}-\mathrm{NMR}$ spectra of PPTDO degradation at different times in $0.25 \mathrm{M} \mathrm{HCl}$ in DMSOd6. The decrease in signal at $13.00 \mathrm{ppm}$ and the increase in signal at $-6.72 \mathrm{ppm}$ is indicative of PPTDO degradation via phosphoramidate linkage cleavage resulting in the formation of phenylphosphoric acid. 


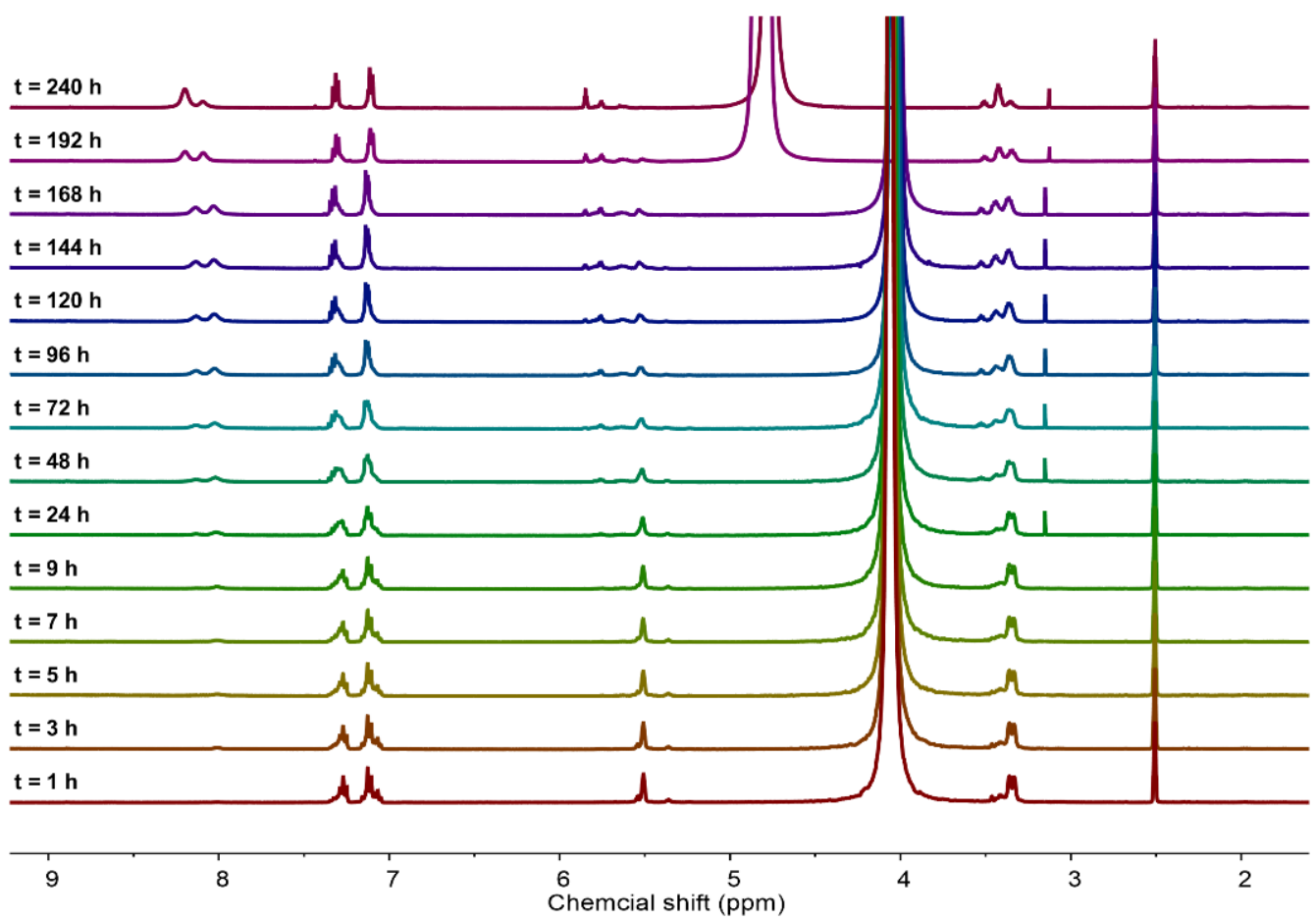

Figure S15. ${ }^{1} \mathrm{H}-\mathrm{NMR}$ spectra of PPTDO degradation at different times in $0.25 \mathrm{M} \mathrm{HCl}$ in DMSOd6. The gradual decrease in signal corresponding to the polyolefin protons at $5.50 \mathrm{ppm}$ is indicative of the degradation of the polymer backbone via acid hydrolysis. 


\section{Copolymerization of PTDO with Norbornenes}

\subsection{Random Copolymerization of PTDO with Norbornenes}
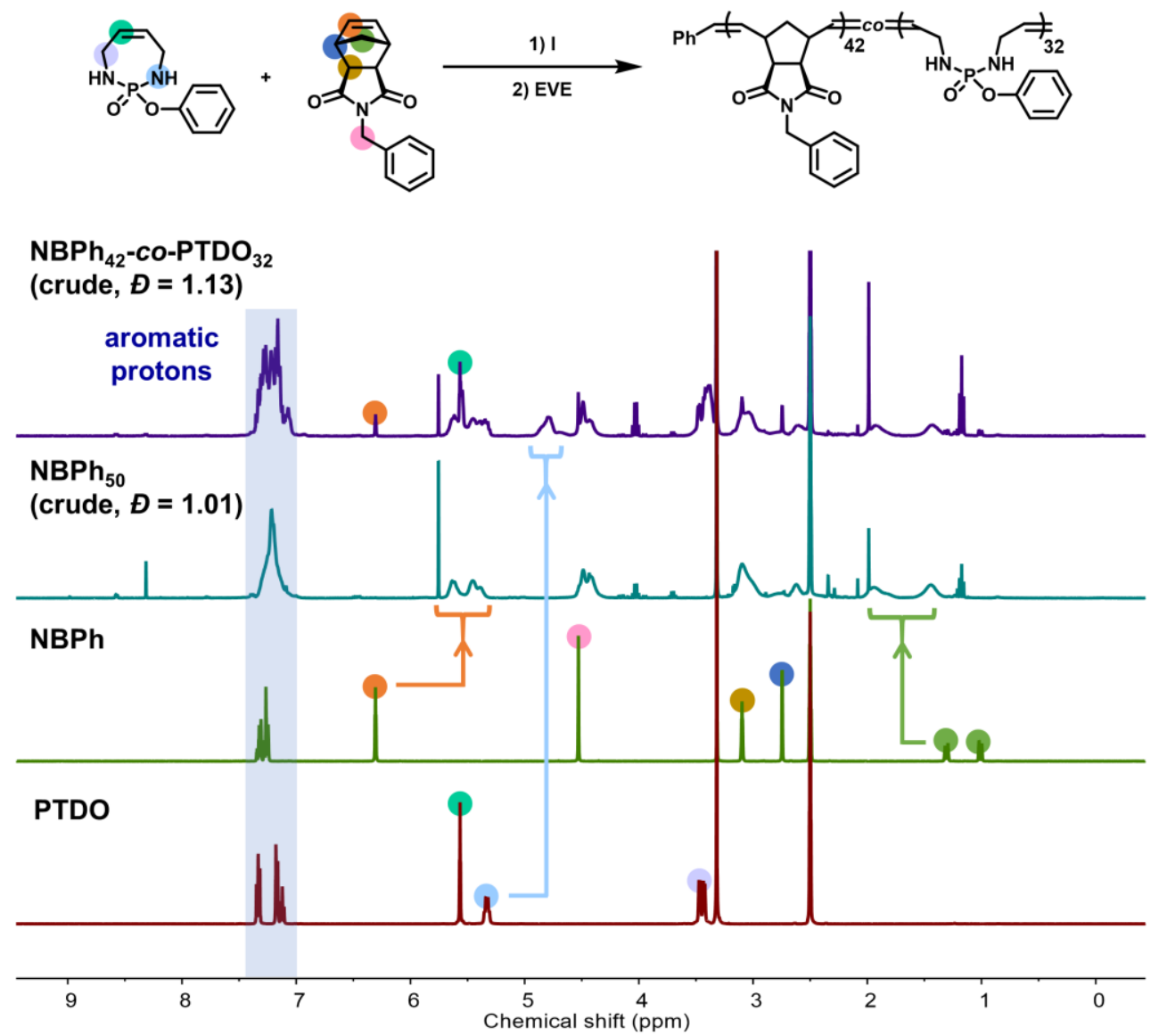

Figure S16. ${ }^{1} \mathrm{H}-\mathrm{NMR}$ spectra of NBPh homopolymerization at $1 \mathrm{~h}$ and copolymerization with PTDO at $5 \mathrm{~h}$. A feed ratio of $50: 50: 1, \mathrm{NBPh}:$ PTDO : I was used. Monomer signals were labeled and assigned to their chemical structures. The signals of olefin and amine shifted after the polymerization as indicated by the arrows. Aromatic protons were used as an internal reference. Integration of the residual norbornene vinyl peak at $6.3 \mathrm{ppm}$ and residual PTDO olefin peak at 5.6 ppm provided $84 \%$ NBPh $(\mathrm{DP}=42)$ and $64 \%$ PTDO (DP $=32$ ) conversion. 

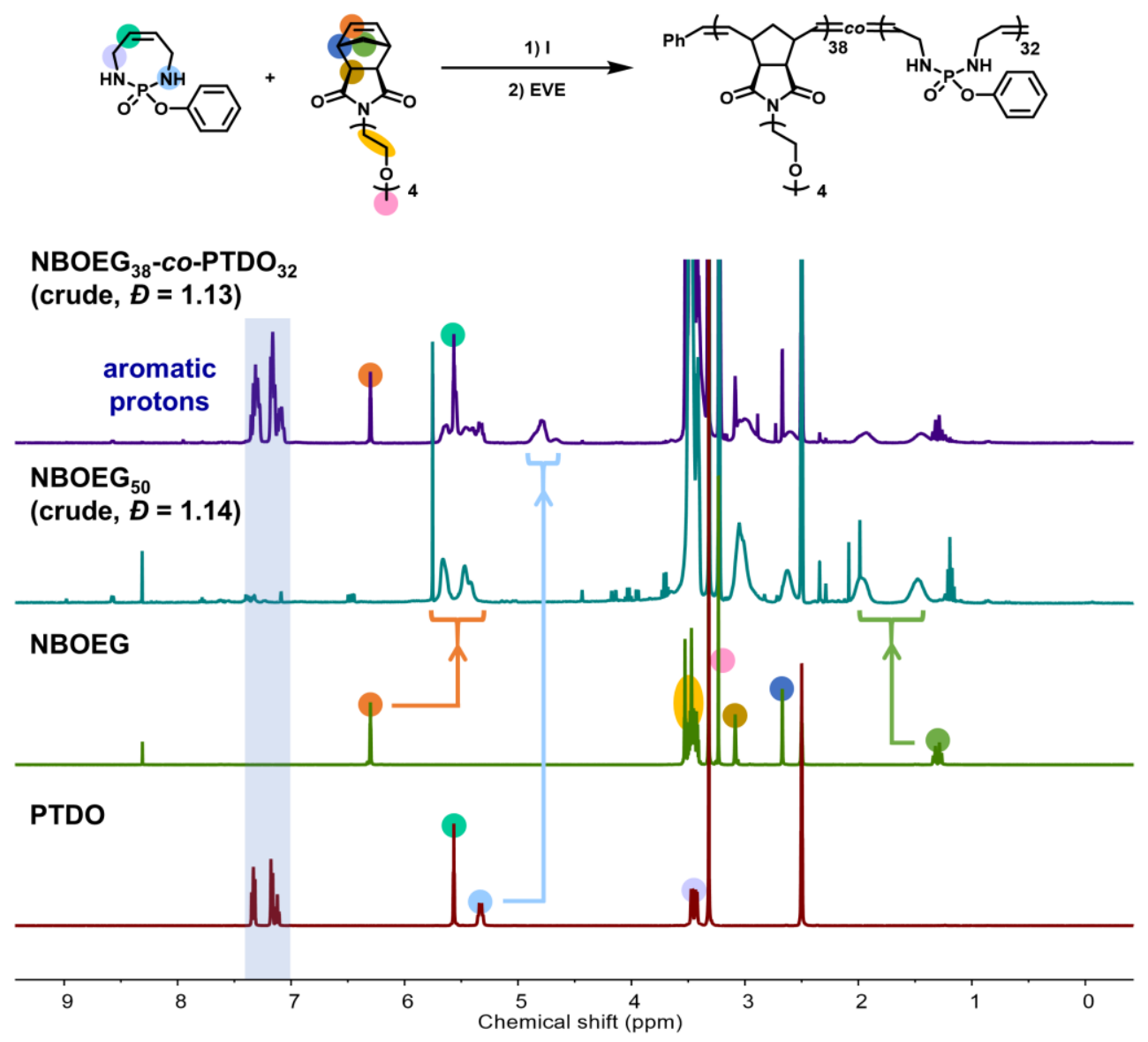

Figure S17. ${ }^{1} \mathrm{H}-\mathrm{NMR}$ spectra of NBOEG homopolymerization at $1 \mathrm{~h}$ and copolymerization with PTDO at $5 \mathrm{~h}$. A feed ratio of $50: 50: 1$, NBOEG : PTDO : I was used. Monomer signals were labeled and assigned to their chemical structures. The signals of olefin and amine shifted after the polymerization as indicated by the arrows. Aromatic protons were used as an internal reference. Integration of the residual norbornene vinyl peak at $6.3 \mathrm{ppm}$ and residual PTDO olefin peak at $5.6 \mathrm{ppm}$ provided $76 \%$ NBOEG $(\mathrm{DP}=38)$ and $64 \%$ PTDO $(\mathrm{DP}=32)$ conversion. 


\subsection{Block Copolymerization of PTDO with Norbornenes}

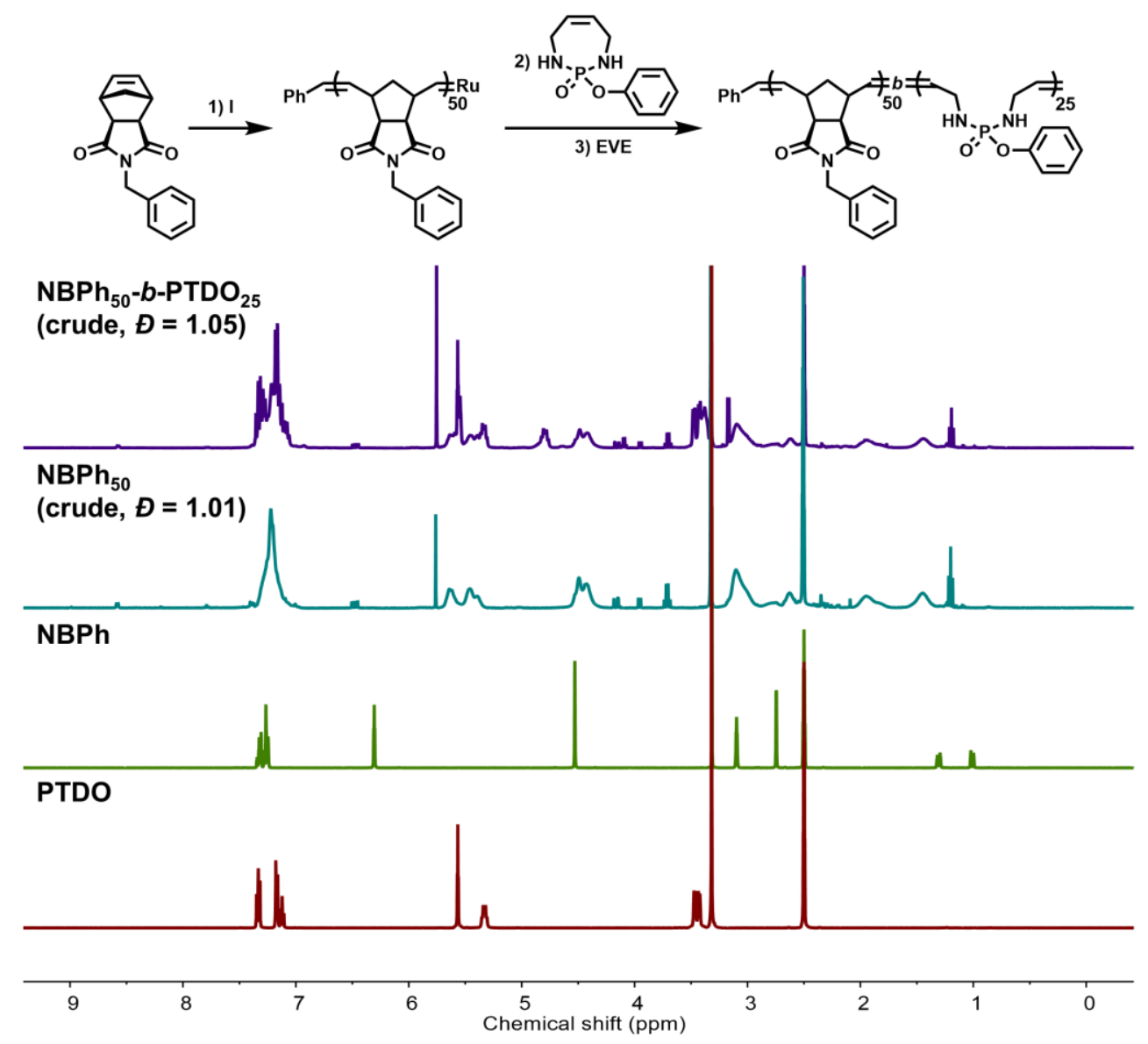

Figure S18. ${ }^{1} \mathrm{H}-\mathrm{NMR}$ spectra of NBPh polymerization at $1 \mathrm{~h}$ and chain extension with PTDO at 3 h. A feed ratio of $50: 50: 1$, NBPh : PTDO : I was used. Integration of the residual monomer and polymer amine signals provided a $50 \%$ PTDO conversion (DP $=25)$. 


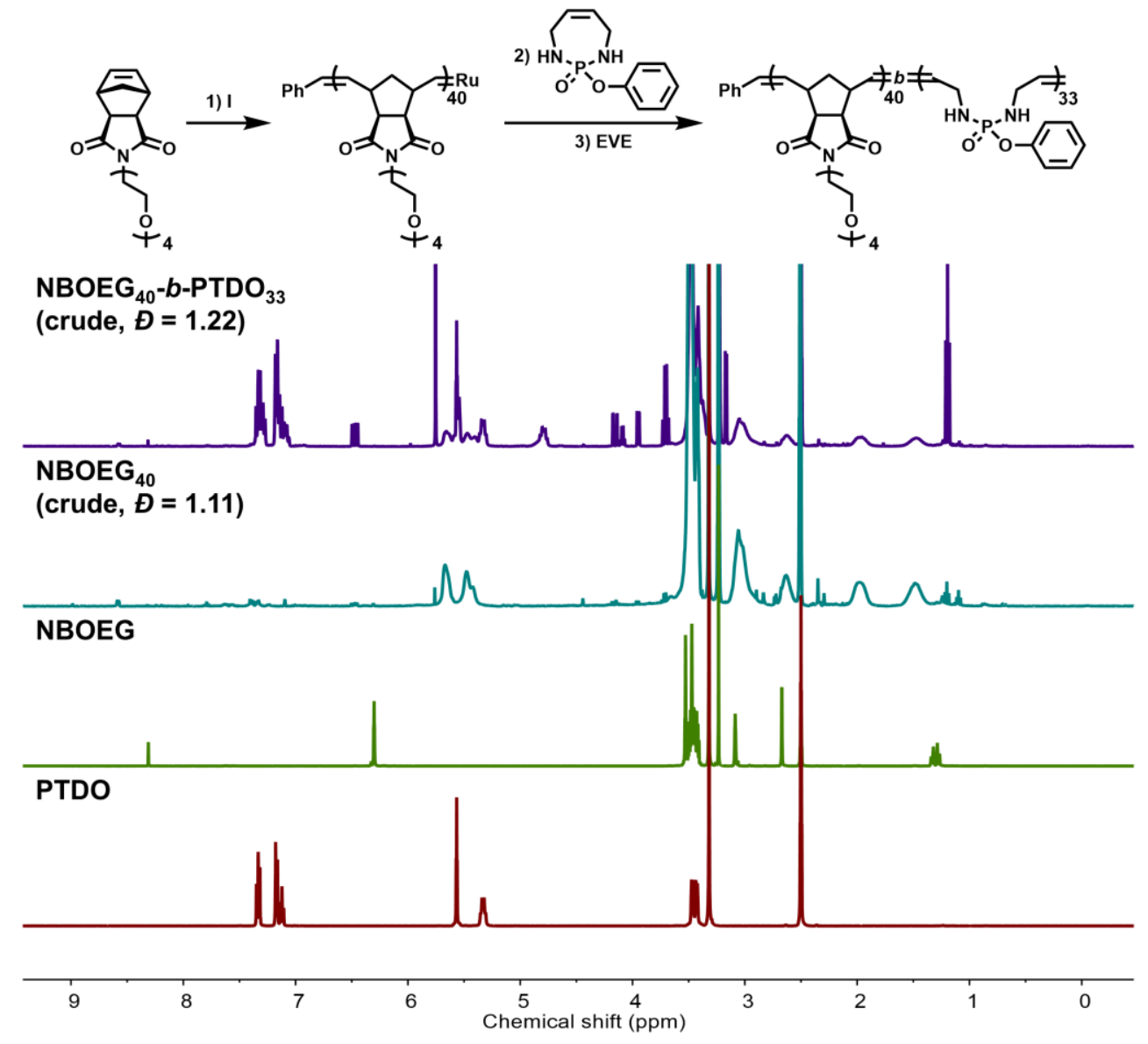

Figure S19. ${ }^{1} \mathrm{H}-\mathrm{NMR}$ spectra of NBOEG polymerization at $1 \mathrm{~h}$ and chain extension with PTDO at $3 \mathrm{~h}$. A feed ratio of $40: 80: 1$, NBOEG : PTDO : I was used. Integration of the residual monomer and polymer amine signals provided a $41 \%$ PTDO conversion (DP $=33)$. 


\section{Micellar Nanoparticle Characterization and Cytotoxicity}

A
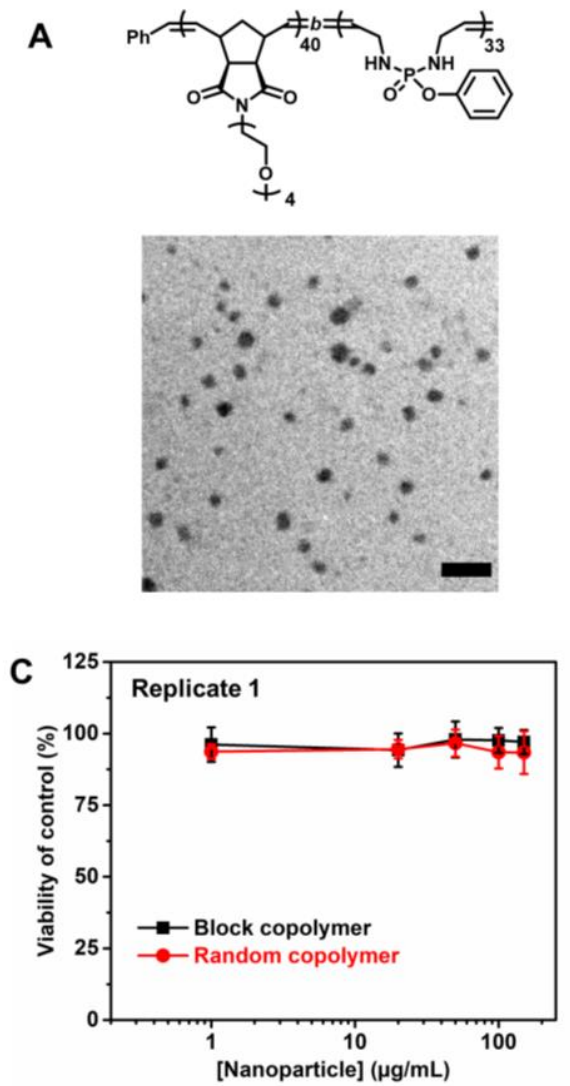

B
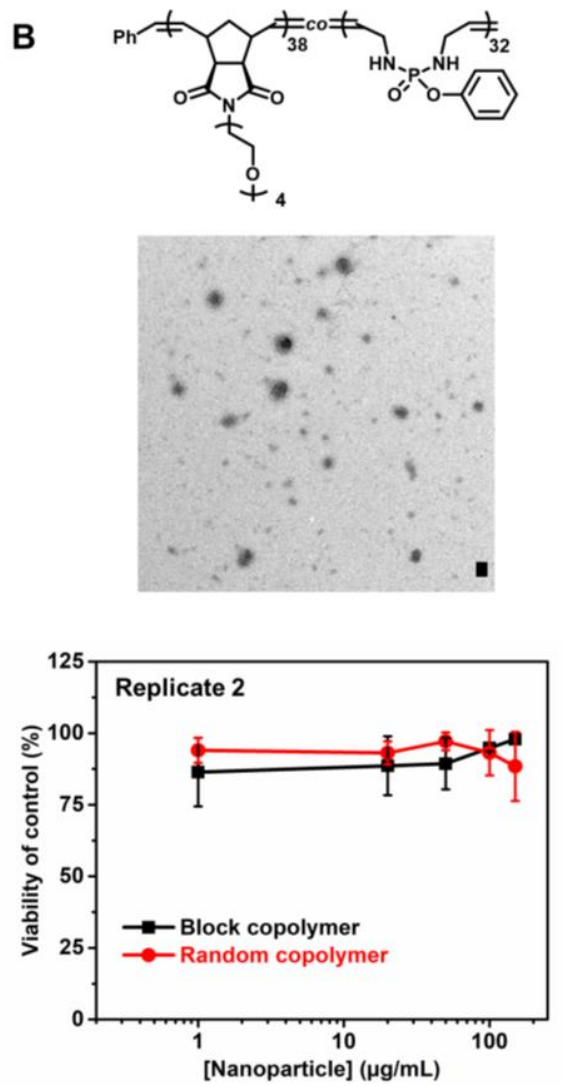

Figure S20. Characterization and cytotoxicity of NB-PTDO nanoparticles. (A-B) TEM images of particles formulated from block and random copolymers. Scale bar: $100 \mathrm{~nm}$. (C) Cell viability of HeLa cells incubated for $24 \mathrm{~h}$ with nanoparticles. Five concentrations: 1, 20, 50, 100, $150 \mu \mathrm{g} / \mathrm{mL}$ were used. Two replicates of the experiment were performed. All values are relative to the cell media control, normalized to $100 \%$. 


\section{NMR Spectra}

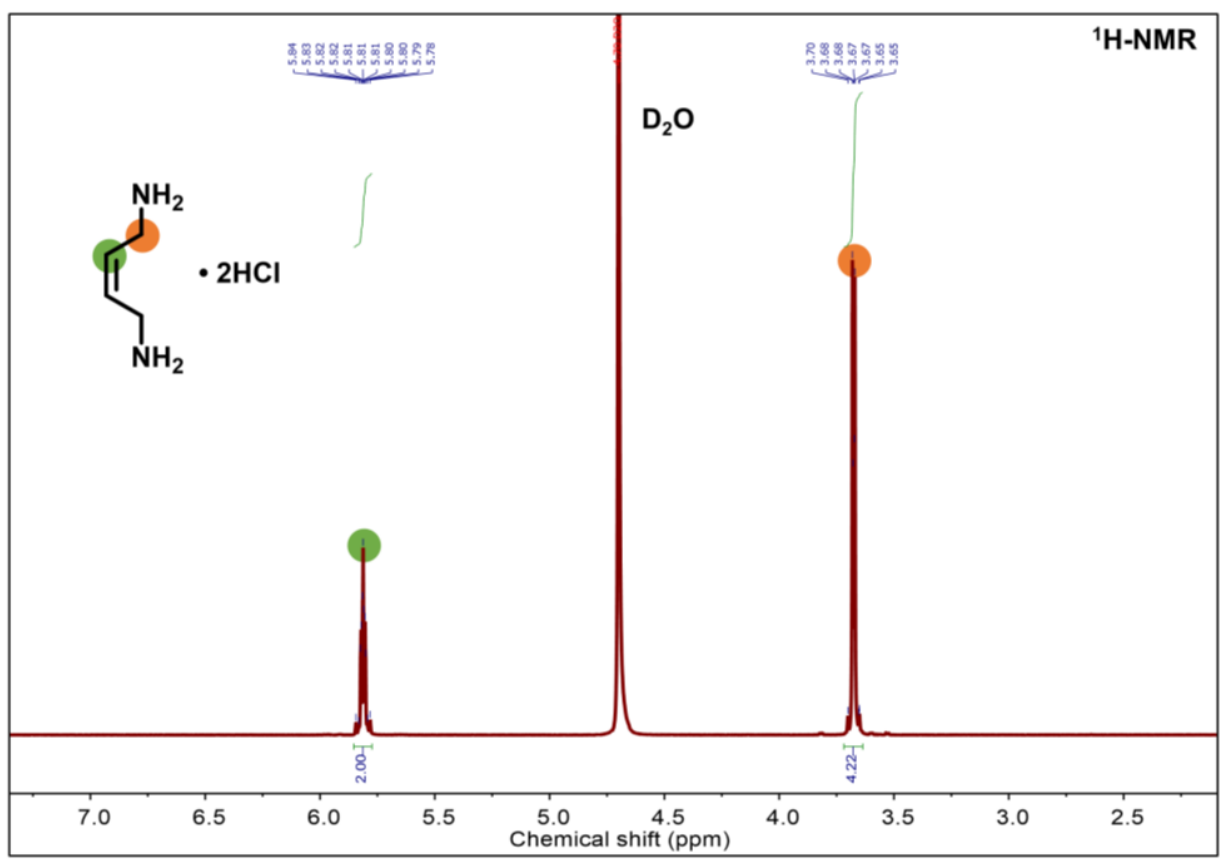

Figure S21. ${ }^{1} \mathrm{H}-\mathrm{NMR}$ spectrum of cis-1,4-diamino-2-butene-2 $\mathrm{HCl}$ in $\mathrm{D}_{2} \mathrm{O}$.

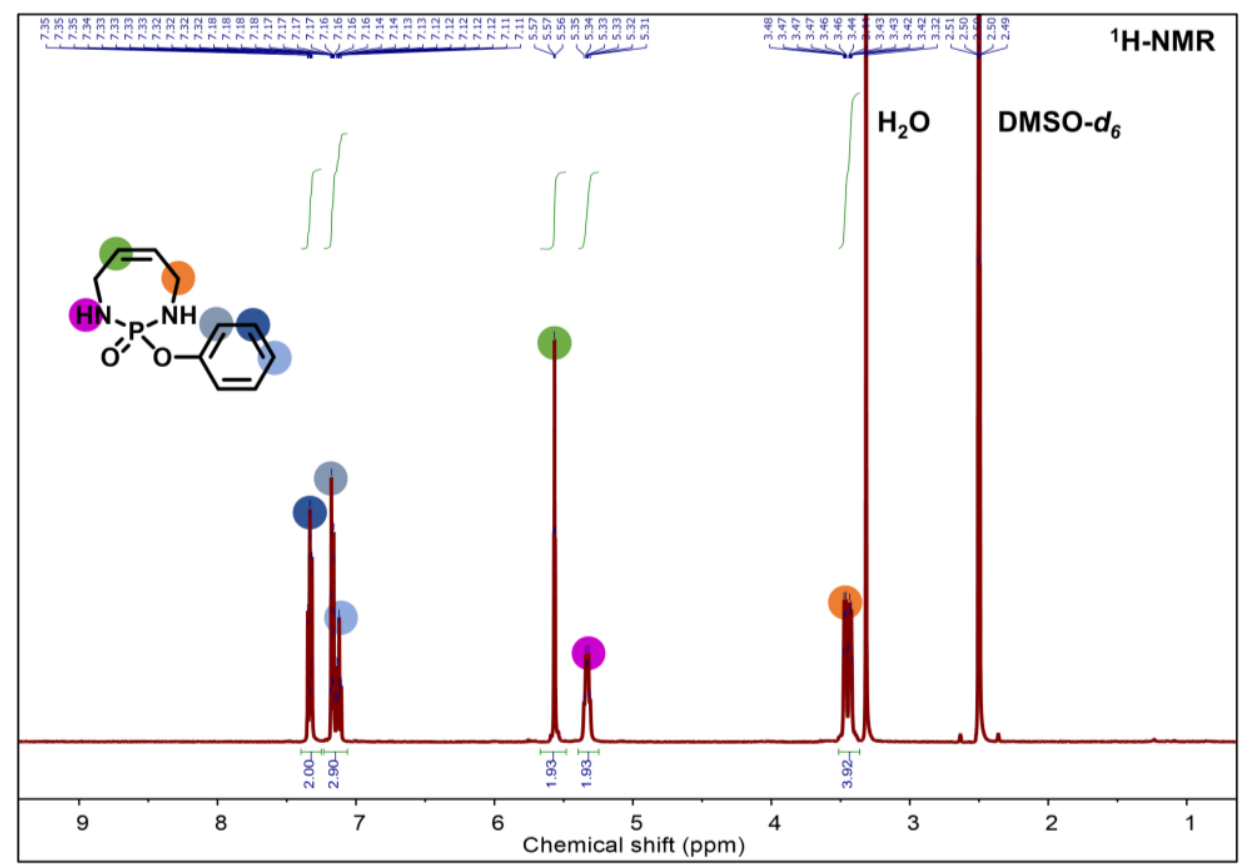

Figure S22. ${ }^{1} \mathrm{H}-\mathrm{NMR}$ spectrum of PTDO in DMSO- $d 6$. 


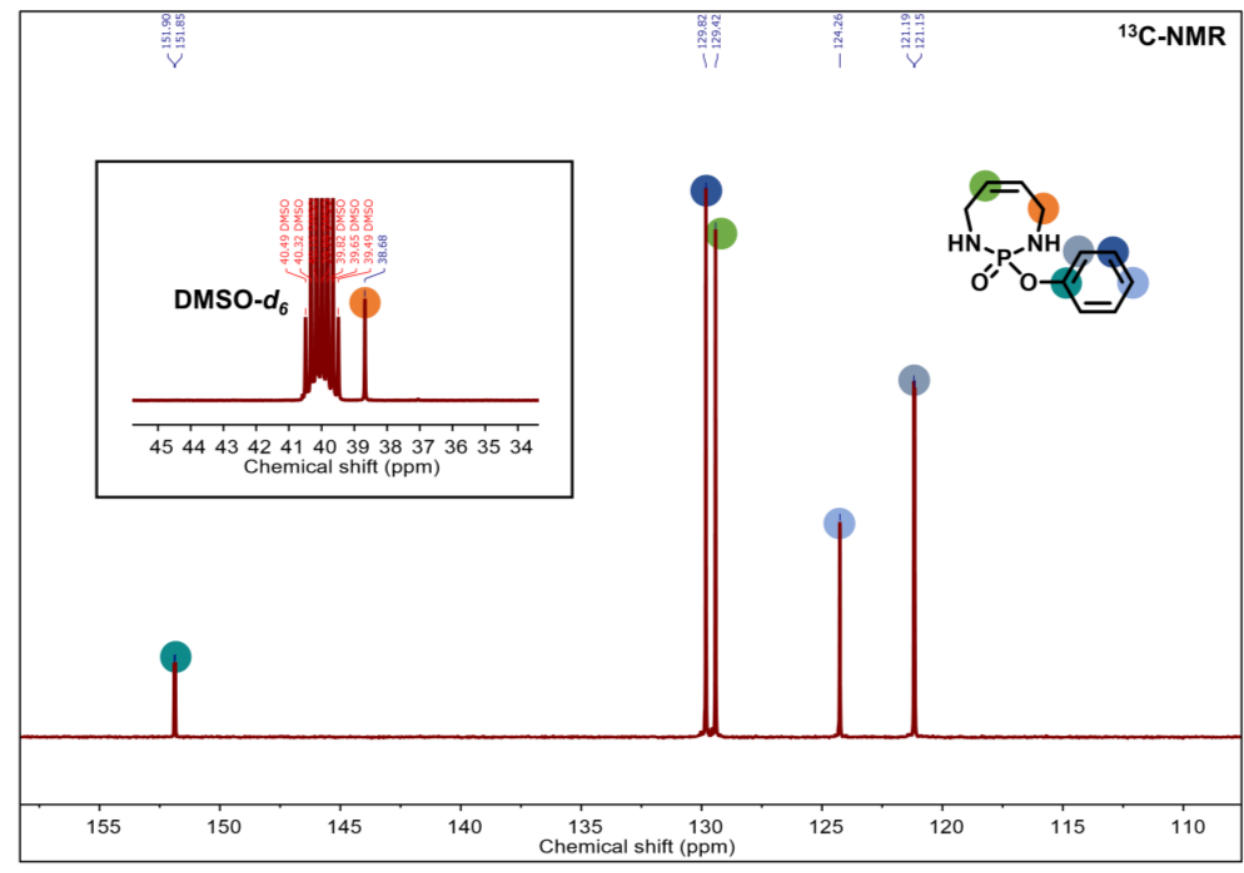

Figure S23. ${ }^{13} \mathrm{C}-\mathrm{NMR}$ spectrum of PTDO in DMSO- $d_{6}$.

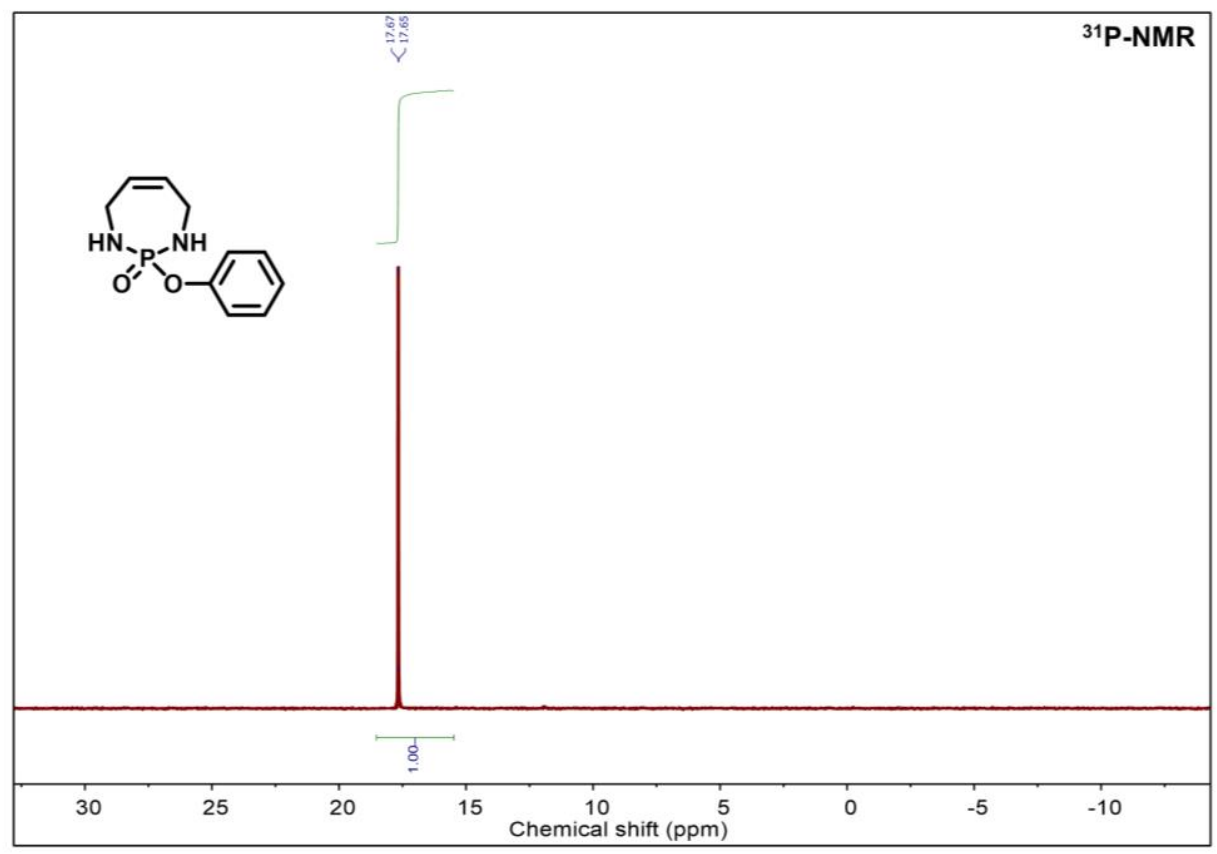

Figure S24. ${ }^{31} \mathrm{P}-\mathrm{NMR}$ spectrum of PTDO in DMSO- $d_{6}$. 


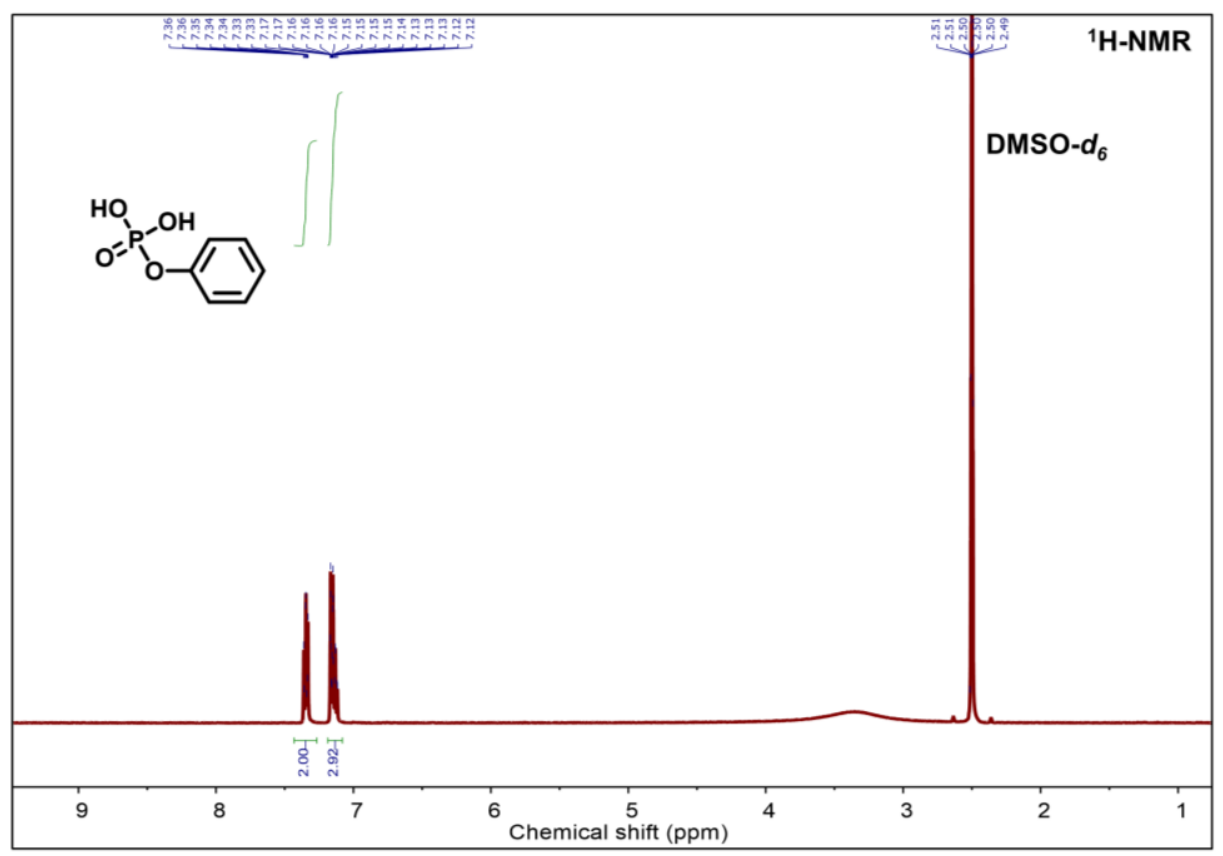

Figure S25. ${ }^{1} \mathrm{H}-\mathrm{NMR}$ spectrum of phenylphosphoric acid in DMSO- $d_{6}$.

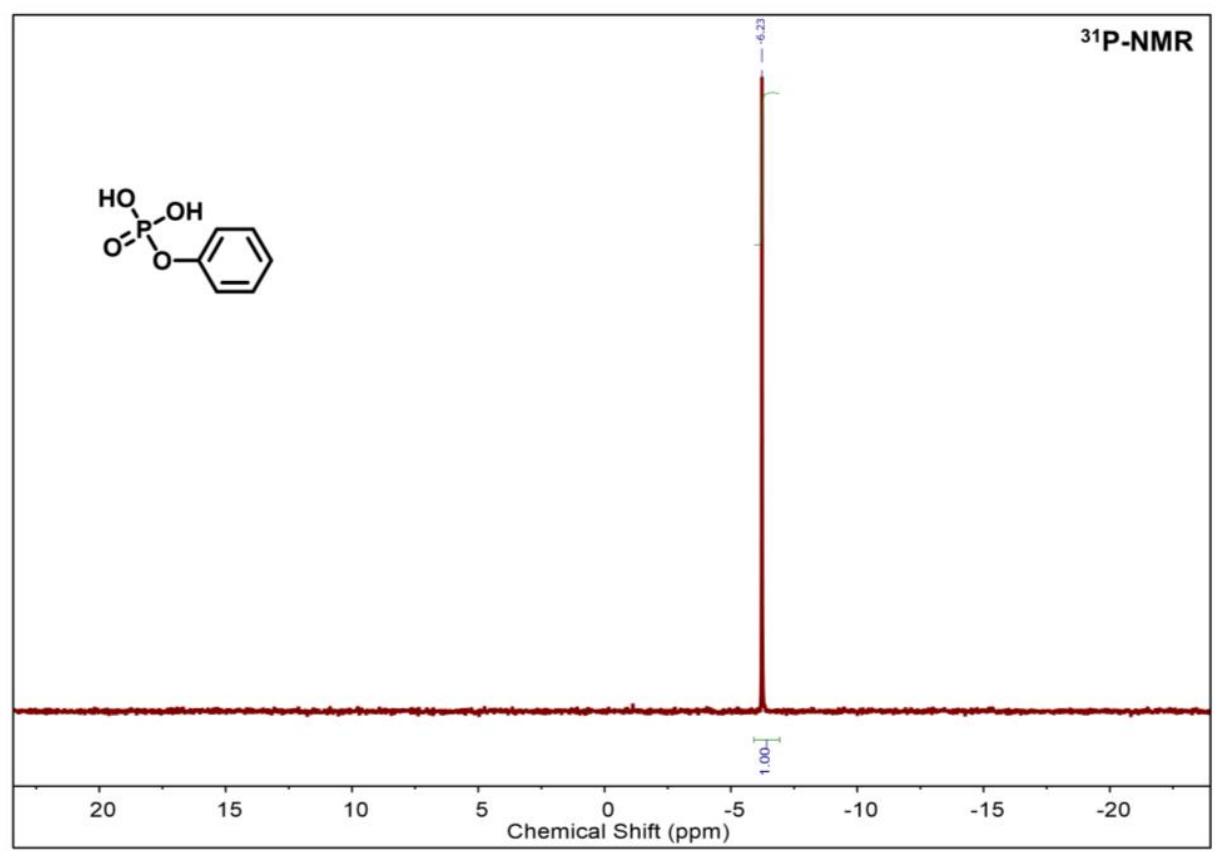

Figure S26. ${ }^{31} \mathrm{P}-\mathrm{NMR}$ spectrum of phenylphosphoric acid in DMSO-d6. 


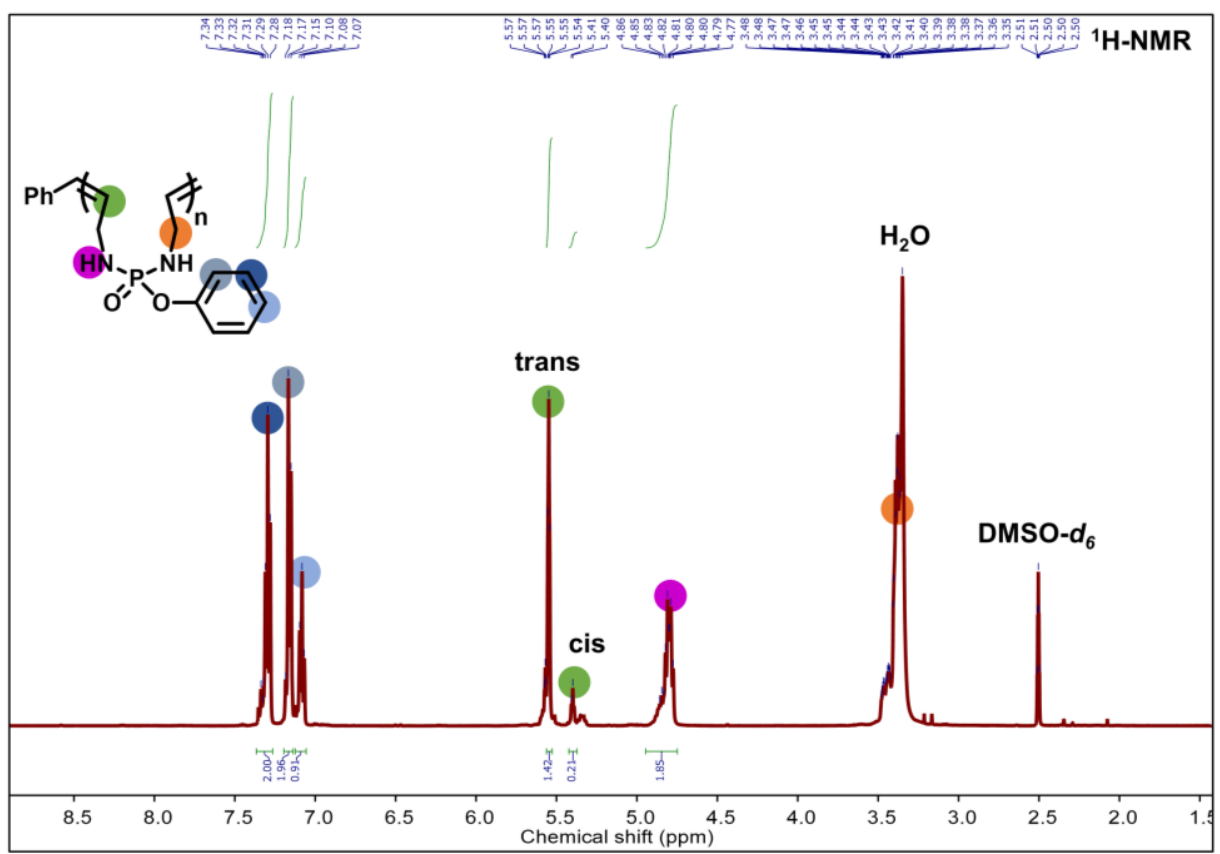

Figure S27. ${ }^{1} \mathrm{H}-\mathrm{NMR}$ spectrum of PPTDO (DP=94) in DMSO-d6. Integration of trans (5.54 ppm) and cis $(5.40 \mathrm{ppm})$ signals revealed an $\mathrm{E} / \mathrm{Z}$ ratio of $7: 1$.

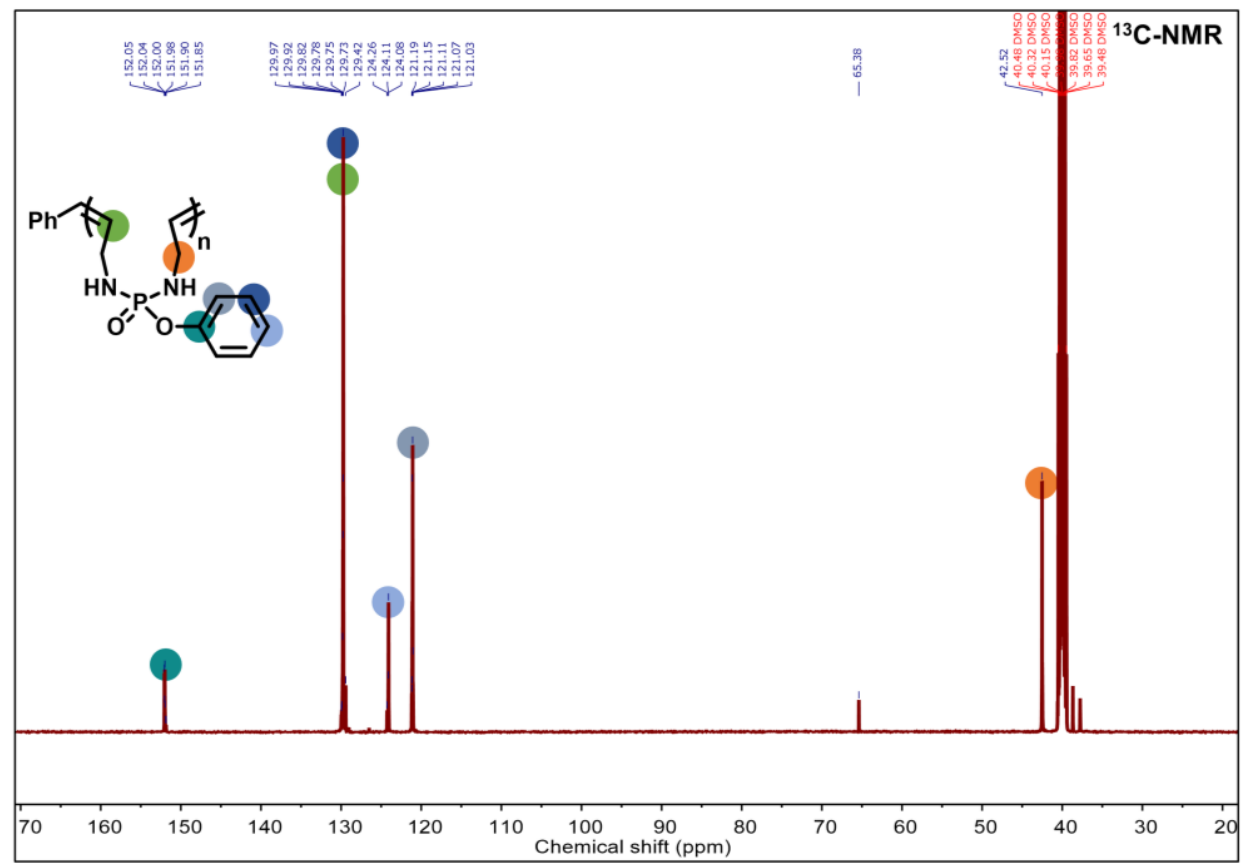

Figure S28. ${ }^{13} \mathrm{C}-\mathrm{NMR}$ spectrum of PPTDO (DP=94) in DMSO- $d_{6}$. 


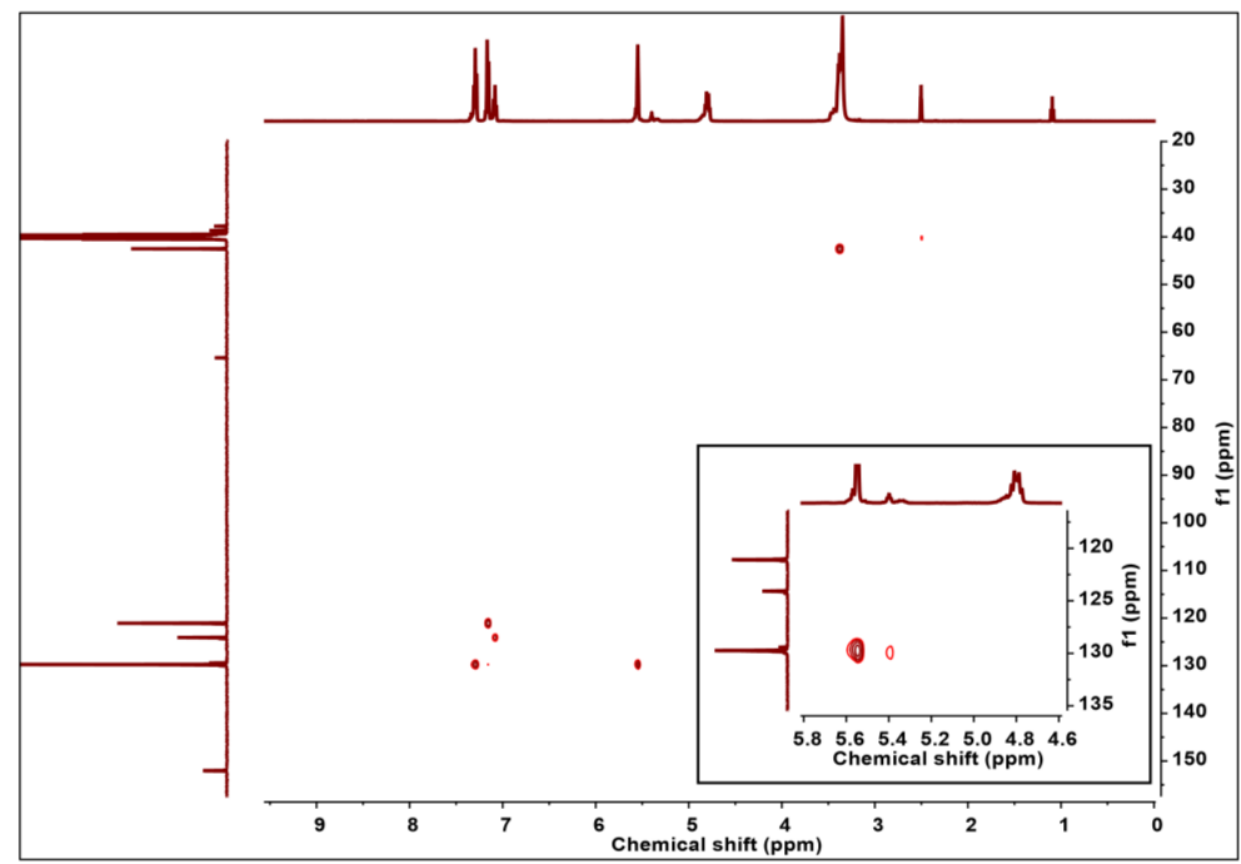

Figure S29. HSQC spectrum of PPTDO (DP=94) in DMSO-d6. $\mathrm{H}$ signals at 5.54 and $5.40 \mathrm{ppm}$ showed a correlation with $\mathrm{C}$ signal at $130 \mathrm{ppm}$, indicating for trans and cis alkene configurations.

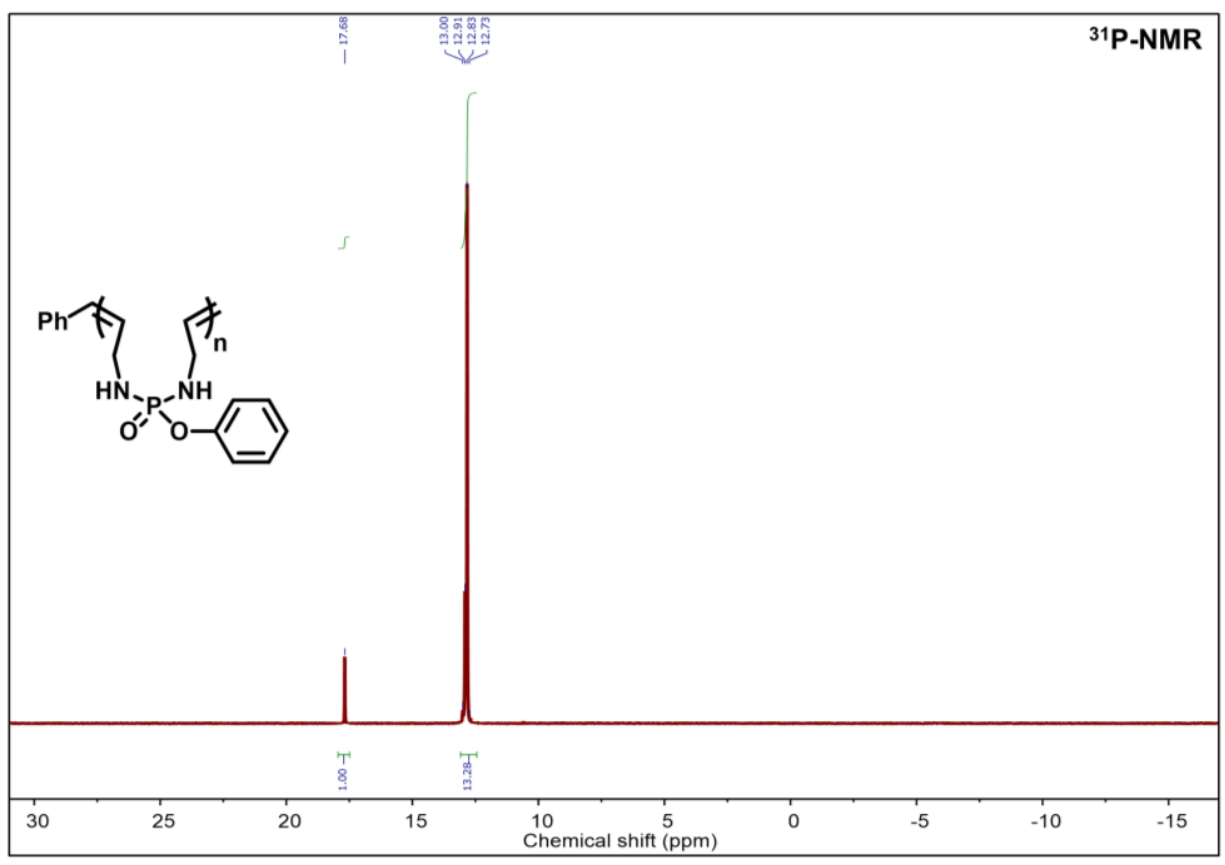

Figure S30. ${ }^{31} \mathrm{P}-\mathrm{NMR}$ spectrum of PPTDO (DP=94) in DMSO-d6. The peak at $17.68 \mathrm{ppm}$ was attributed to the residual PTDO monomer after repeated precipitation purification (three times). 


\section{References}

1. Thompson, M. P.; Randolph, L. M.; James, C. R.; Davalos, A. N.; Hahn, M. E.; Gianneschi, N. C. Labelling polymers and micellar nanoparticles via initiation, propagation and termination with ROMP. Polym. Chem. 2014, 5, 1954-1964.

2. Huang, W. M.; Zhu, Z. S.; Wen, J.; Wang, X.; Qin, M.; Cao, Y.; Ma, H. B.; Wang, W. Single Molecule Study of Force-Induced Rotation of Carbon-Carbon Double Bonds in Polymers. ACS Nano. 2017, 11, 194-203.

3. Nagarkar, A. A.; Crochet, A.; Fromm, K. M.; Kilbinger, A. F. M. Efficient Amine EndFunctionalization of Living Ring-Opening Metathesis Polymers. Macromolecules. 2012, 45, 44474453.

4. Sun, H.; Kabb, C. P.; Dai, Y. Q.; Hill, M. R.; Ghiviriga, I.; Bapat, A. P.; Sumerlin, B. S. Macromolecular metamorphosis via stimulus-induced transformations of polymer architecture. Nat. Chem. 2017, 9, 817-823.

5. Shao, Y.; Molnar, L. F.; Jung, Y.; Kussmann, J.; Ochsenfeld, C.; Brown, S. T.; Gilbert, A. T. B.; Slipchenko, L. V.; Levchenko, S. V.; O'Neill, D. P.; DiStasio, R. A.; Lochan, R. C.; Wang, T.; Beran, G. J. O.; Besley, N. A.; Herbert, J. M.; Lin, C. Y.; Van Voorhis, T.; Chien, S. H.; Sodt, A.; Steele, R. P.; Rassolov, V. A.; Maslen, P. E.; Korambath, P. P.; Adamson, R. D.; Austin, B.; Baker, J.; Byrd, E. F. C.; Dachsel, H.; Doerksen, R. J.; Dreuw, A.; Dunietz, B. D.; Dutoi, A. D.; Furlani, T. R.; Gwaltney, S. R.; Heyden, A.; Hirata, S.; Hsu, C. P.; Kedziora, G.; Khalliulin, R. Z.; Klunzinger, P.; Lee, A. M.; Lee, M. S.; Liang, W.; Lotan, I.; Nair, N.; Peters, B.; Proynov, E. I.; Pieniazek, P. A.; Rhee, Y. M.; Ritchie, J.; Rosta, E.; Sherrill, C. D.; Simmonett, A. C.; Subotnik, J. E.; Woodcock, H. L.; Zhang, W.; Bell, A. T.; Chakraborty, A. K.; Chipman, D. M.; Keil, F. J.; Warshel, A.; Hehre, W. J.; Schaefer, H. F.; Kong, J.; Krylov, A. I.; Gill, P. M. W.; Head-Gordon, M. Advances in methods and algorithms in a modern quantum chemistry program package. Phys. Chem. Chem. Phys. 2006, 8, 3172-3191. 